\title{
Differential Diagnosis between Neoplastic and Non-Neoplastic Brain Lesions in Radiology
}

\section{Diagnóstico diferencial entre lesões cerebrais neoplásicas e não neoplásicas em radiologia}

\author{
Nícollas Nunes Rabelo ${ }^{1}$ Luciano José Silveira Filho ${ }^{1}$ Bruno Nascimento Bithencurt da Silva ${ }^{1}$ \\ Christien Dannemberg Cunha ${ }^{1}$ Igor de Souza Furtado ${ }^{1}$ Daniel Alves Branco Valli ${ }^{1}$ \\ Vitor Hugo Honorato Pereira ${ }^{1}$ George Santos dos Passos ${ }^{1}$ Marco Aurélio Ferrari Sant'Anna ${ }^{2}$ \\ Neiffer Nunes Rabelo ${ }^{3}$ Luiz Antônio Araujo Dias ${ }^{4}$ Luiz Antônio Araujo Dias Junior ${ }^{5}$ Koji Tanaka ${ }^{5}$ \\ Fernando Eduardo Plastina ${ }^{5}$
}

\footnotetext{
${ }^{1}$ Neurosurgery Resident, Department of Neurosurgery, Santa Casa Hospital; Ribeirão Preto, São Paulo, Brazil

2 Medical Student, Centro Universitário Barão de Mauá, Ribeirão

Preto, São Paulo, Brazil

3 Medical Student, Faculdade Atenas, Paracatu, Minas Gerais, Brazil

${ }^{4}$ Neurosurgeon and Professor, Neurosurgery Department, Santa Casa Hospital; Ribeirão Preto, SP, Brazil

${ }^{5}$ Neurosurgeon, Department of Neurosurgery, Santa Casa Hospital; Ribeirão Preto, São Paulo, Brazil
}

Address for correspondence Nícollas Nunes Rabelo, MD, Av. Antonio Diederichsen, 190/ap.193, Jardim América, Ribeirão Preto, SP, Brazil 14020-250 (e-mail: nicollasrabelo@hotmail.com).

Arq Bras Neurocir 2016;35:45-61.

\begin{abstract}
Keywords

- hypodensities

- computed tomography scan

- neoplastic lesions

- non-neoplastic lesions

- MRI

Introduction The observation of multiple lesions in a skull computed tomography (CT) scan is always cause for concern because of the frequent possibility of neoplastic etiology, although granulomatous, infectious, vascular, iatrogenic, demielinating, trauma, parasitic diseases, and strokes can produce a similar aspect on radiology. A wide range of non-neoplastic conditions can mimic a brain tumor, both clinically and radiologically, representing a potential pitfall for physicians involved in patient care. The study's goal is to alert specialists to the possibility of other neoplastic and nonneoplastic etiologies in the differential diagnosis of hypodense lesions in non-contrast. Methods We performed a literature review using PubMed, Medline, Science Direct, Embase, Clinical Trials, Ebsco, and Scielo. Articles were selected in the period of 1986 to 2015.

Discussion Knowledge of various etiologies when with multiple lesions appear on computed tomography allows specialists to guide the diagnosis to appropriate treatment, avoiding the irradiation of non-neoplastic lesions and unnecessary surgeries. The most common lesions were the neoplasm (74\% to $86 \%$ ), especially gliomas, followed by infections ( $8 \%$ to $15 \%$ ), and infarcts $(0.6 \%$ to $6 \%$ ), which represent nonneoplastic lesions.
\end{abstract}

received

June 9, 2015

accepted

November 23, 2015

published online

February 3, 2016
DOI http://dx.doi.org/

10.1055/s-0035-1570362. ISSN 0103-5355.
Copyright $\odot 2016$ by Thieme Publicações License terms Ltda, Rio de Janeiro, Brazil 


\section{Resumo}

\author{
Palavras-chave \\ - hipodensidades \\ - tomografia de crânio \\ - lesões neoplásicas \\ - lesões não \\ neoplásicas \\ - ressonância \\ magnética
}

Conclusion Given the relatively high percentage of wrong neuroradiology diagnoses, most cases may require histological diagnosis, because even magnetic resonance imaging (MRI) renders difficulties in distinguishing such lesions.

Introdução Observação de múltiplas lesões na tomografia computadorizada de crânio (TC) é sempre motivo de preocupação por causa da possibilidade frequente de etiologia neoplásica, embora as doenças granulomatosas, infecciosas, vascular, iatrogênica, desmielinizante, trauma, e parasitárias podem produzir aspecto semeIhante na radiologia. Uma ampla gama de condições não neoplásicas pode mimetizar um tumor cerebral, tanto clínica, quanto radiologicamente, representando uma armadilha potencial para os médicos envolvidos no cuidado ao paciente. O objetivo do estudo é alertar a possibilidade de outras etiologias neoplásicas e não neoplásicas no diagnóstico diferencial de lesões hipodensas em TC sem contraste.

Métodos Revisão da literatura utilizando PubMed, MEDLINE, Google Scholar, Ensaios Clínicos, EBSCO, Scielo, Tópicos em radiologia. Foram selecionados por período 19862015.

Discussão O conhecimento de várias etiologias, quando confrontado com múltiplas lesões na tomografia computadorizada permite o direcionamento do diagnóstico para o tratamento adequado, evitando a irradiação de lesões não neoplásicas e cirurgias desnecessárias. As lesões mais frequentes são neoplasias (74\% a $86 \%$ ), especialmente gliomas, seguido de infecções ( $8 \%$ a $15 \%$ ) e infartos $(0,6 \%$ a $6 \%$ ), que representam lesões não neoplásicas.

Conclusão Como um possível resultado da percentagem relativamente elevada de diagnósticos errados neurorradiológicos, o diagnóstico histológico faz necessário, porque mesmo Ressonância pode ser difícil na diferenciação de tais lesões.

\section{Introduction}

In this review, we discuss some clinically and radiologically presentations as intracranial mass lesions. In each case, the researchers initially considered tumors. However, pathology revealed that a variety of neoplastic etiologies, such as granulomatous, infectious, vascular, iatrogenic, demyelinating, and parasitic diseases, as well as trauma and strokes can produce a similar aspect on radiology. Although the tumor is often the most likely diagnostic considered in a patient presenting with a contrast-enhancing mass lesion within the brain parenchyma with surrounding edema and mass effect, it is not always the case. Not uncommonly, there can be significant overlap in the radiologic presentation between neoplastic and nonneoplastic diseases. Both neoplastic and nonneoplastic diseases can produce abnormal contrast enhancement, mass effect, and perilesional edema on both the computed tomography (CT), which is the most used, and the magnetic resonance imaging (MRI). Occasionally, some of these nonneoplastic etiologies may produce signs and symptoms clinically mimicking tumoral disease. ${ }^{1}$ As such, these situations pose a diagnostic challenge to both the clinician and radiologist, and often such patients undergo biopsy. In most cases, the pathologist can readily differentiate between neoplasia and nonneoplastic imitators. However, because the benign nature of some pseudoneoplastic lesions may not be immediately apparent in the pathologic examination, the pathologist should be aware of their existence. Our study's goal is to alert pathologists, radiologists, neurologists, neurosurgeons, and other physicians involved in the care of neurooncological patients, of the possibility of other neoplastic and non-neoplastic etiologies in the differential diagnosis of hypodense lesions in non-contrast. ${ }^{2,3}$

\section{Methods}

We performed a literature review using PubMed, Medline, Science Direct, Embase, Clinical Trials, Ebsco, and Scielo. Articles were selected in the period of 1986 to 2015. Verified data records, clinical history and brought discussion of the case in scientific service meetings. The search resulted in total 42 papers that the inclusion criteria.

\section{Infections}

\section{Aspergilloma}

The radiological finding of skull base erosion by this mass lesion may contribute to its interpretation as a destructive tumor, with differential diagnosis including chondrosarcoma, metastatic lesion, osteosarcoma, and meningioma. ${ }^{1}$ Although most commonly occurring as an opportunistic infection in immunocompromised patients, aspergilloma is 
well-described in immunocompetent patients, especially in situations where local infections of the ears or sinuses. The growing incidence of Fungal Disease in the Central Nervous System reported by physicians and pathologists can be attributed to the increasing number of immunocompromised patients, which is a consequence of widespread use of immunosuppressive drugs, diabetic populations and a growing number of virus infection of survivor's human immunodeficiency virus (HIV). ${ }^{2,3}$

Usually, cerebral aspergillosis is a result of hematogenous dissemination or, alternatively, by direct extension from an adjacent focus. Aspergillus infection of the central nervous system (CNS) may present as an abscess or as cerebral infarcts, but rarely as meningitis. The aspergilloma can also present as an extra-axial mass extending inside the brain parenchyma. Radiologically, granulomas with fungi present appear as masses. Adjacent to dura mater, they can simulate meningiomas. ${ }^{4}$ In computed tomography, they can be associated with paranasal and small areas of bone destruction sinusitis. Their appearance on MRI may vary depending on the organism involved. Aspergillomas tend to show injury surrounded by perilesional edema in T2. Other fungal infections, such as histoplasmosis, also radiologically simulate brain tumors. Treatment may require a combination of surgical (abscess drainage) and clinical (drugs, amphotericin) procedures (-Fig. 1) $\cdot^{5,6}$

\section{Cryptococcosis}

In immunocompromised patients, infection by the fungus Cryptococcus neoformans typically results in a diffuse meningitis and infiltration of the perivascular spaces. This can lead to the formation of small intraparenchymal gelatinous pseudocysts with little or no inflammatory response. In immunocompetent individuals with a chronic granulomatous reaction, the infection involves microorganisms without neovascular growth around the granulomas, which produces contrast enhancement similar to that of primary or secondary brain tumors. ${ }^{7,8}$ The involvement of the central nervous system by the fungus $C$. neoformans most commonly occurs in the cerebellum, brain stem, and basal ganglia. The radiological distinction between cerebral cryptococcosis and tumors or abscesses from other infections tends to be laborious and meticulous due to a lack of characteristics unique to cerebral cryptococcosis. Brain injuries can reveal cryptococcosis surrounding edema and focal calcification internally to injury. The pituitary gland is rarely affected by this infection. Treatment consists of surgical removal of cryptococcoma and subsequent treatment with drugs and amphotericin fluorocytosine (-Fig. 2). ${ }^{9,10}$

\section{Whipplés Disease}

Whipple's disease is a rare illness caused by Gram-negative bacilli Tropheryma whipplei, characterized by chronic inflammation that primarily affects the gastrointestinal tract and musculoskeletal system. The classic presentation includes fever, steatorrhea, weight loss, lymphadenopathy, and recurrent arthritis. The central nervous system is affected in approximately $6 \%$ to $43 \%$ of patients with Whipple's disease. Radiologically, the lesions are hyperintense on T2weighted MRI and can show homogeneous enhancement ring. Usually they have variable perilesional edema. The disease, when it affects the CNS, may manifest itself in two ways: the focal form, with a single mass, or multiple lesions causing various symptoms. After mass resection, it is possible to see a perivascular infiltrate of foamy macrophages and positive PAS (Periodic Acid Shift). Such lesions simulate lowgrade gliomas. Treatment consists of antibiotics (penicillin, tetracycline) (-Fig. 3). ${ }^{11-13}$

\section{Bacterial Abscess}

Radiological differentiation between pyogenic abscesses and brain tumors can be a challenge, as both commonly show ring and perilesional edema enhancement. A useful finding in MRI is the presence of a hypointense capsule in T2weighted images, which is not typically seen in tumors. Treatment consists of surgical drainage of the abscess associated with antibiotic therapy (-Fig. 4). ${ }^{14,15}$

\section{Nocardiosis}

Nocardiosis is an infectious disease caused by bacteria of the genus Nocardia that affects humans and animals. ${ }^{6}$ The brain abscess resulting from this infection is rare, however, can
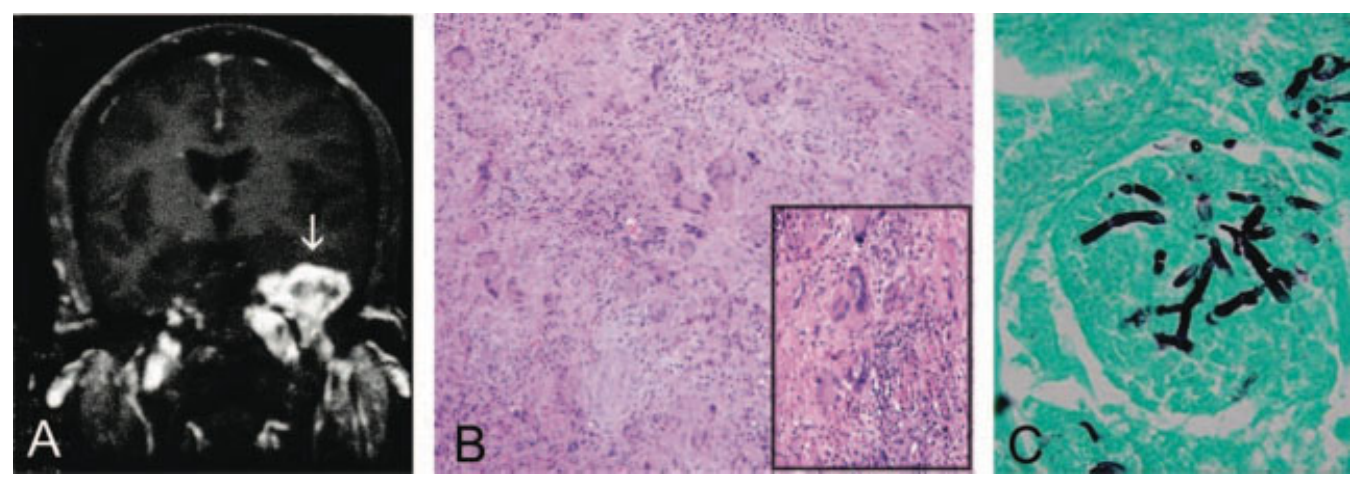

Fig. 1 (A) Coronal T1-weighted magnetic resonance imaging demonstrating a centrally hypointense lesion (arrow) within the left temporal bone with irregular contrast enhancement. (B) Granulomatous inflammation (hematoxylin-eosin, original magnification 200). Inset, Multinucleate giant cells (hematoxylin-eosin, original magnification 400). (C) Fungal hyphae with acute angle branching (Gomori methenamine silver stain, original magnification 400). Pathologic diagnosis: aspergilloma. 

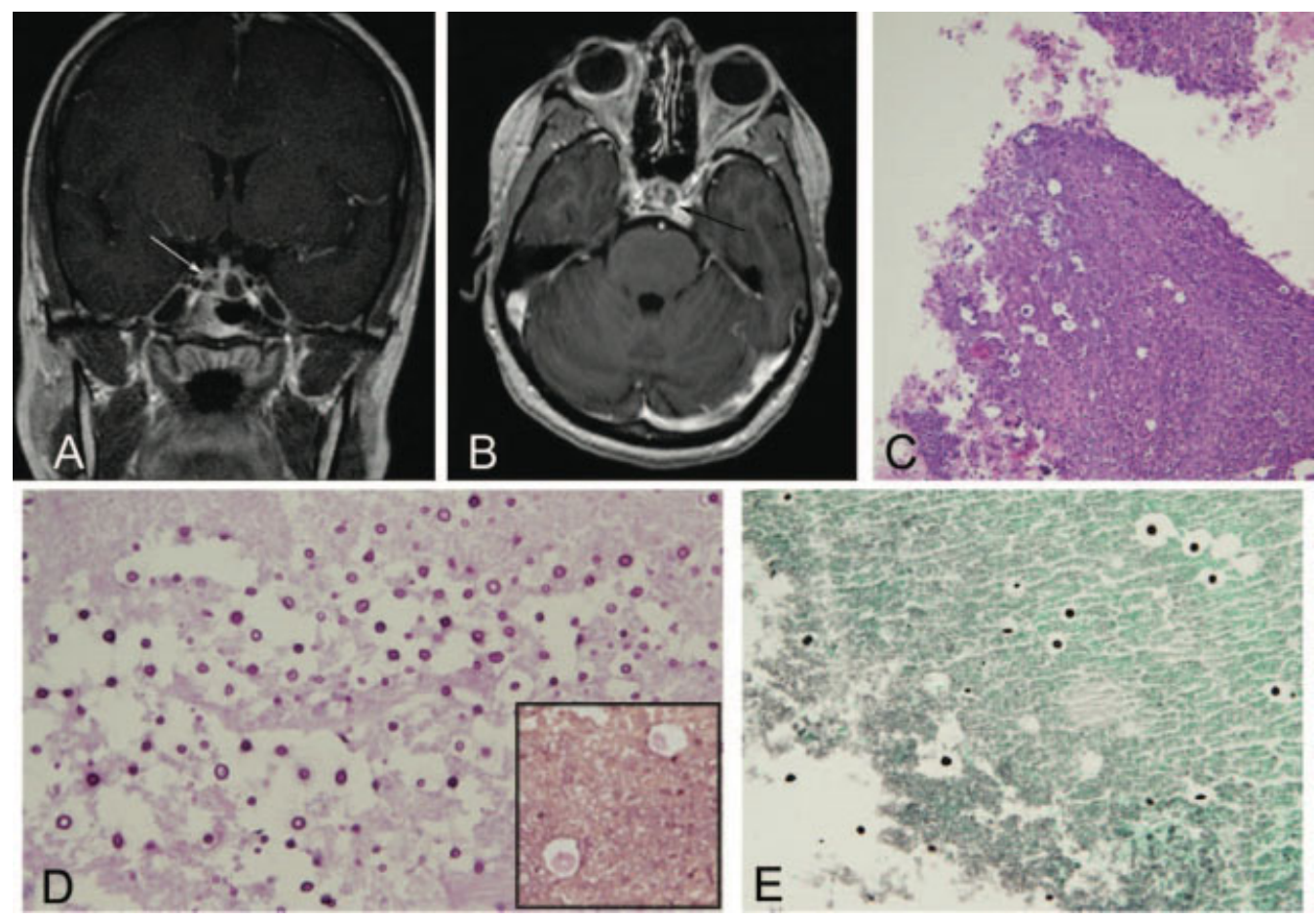

Fig. 2 (A) Coronal T1-weighted magnetic resonance imaging (MRI) demonstrating a centrally hypointense intrasellar mass (arrow) with a thin rim of peripheral enhancement. (B) Axial T1-weighted MRI demonstrating a low signal intensity mass (arrow) within the sella with thin peripheral enhancement and a thin enhancing septation. (C) Necrotic basophilic material containing small- to medium-sized oval yeast forms (hematoxylineosin, original magnification 200). (D) Organisms are strongly periodic acid-Schiff positive (original magnification 400). Inset, Capsule of organism is weakly mucicarmine positive (original magnification 400). (E) Organisms are strongly labeled by Gomori methenamine silver stain (original magnification 400). Pathologic diagnosis: cryptococcoma.
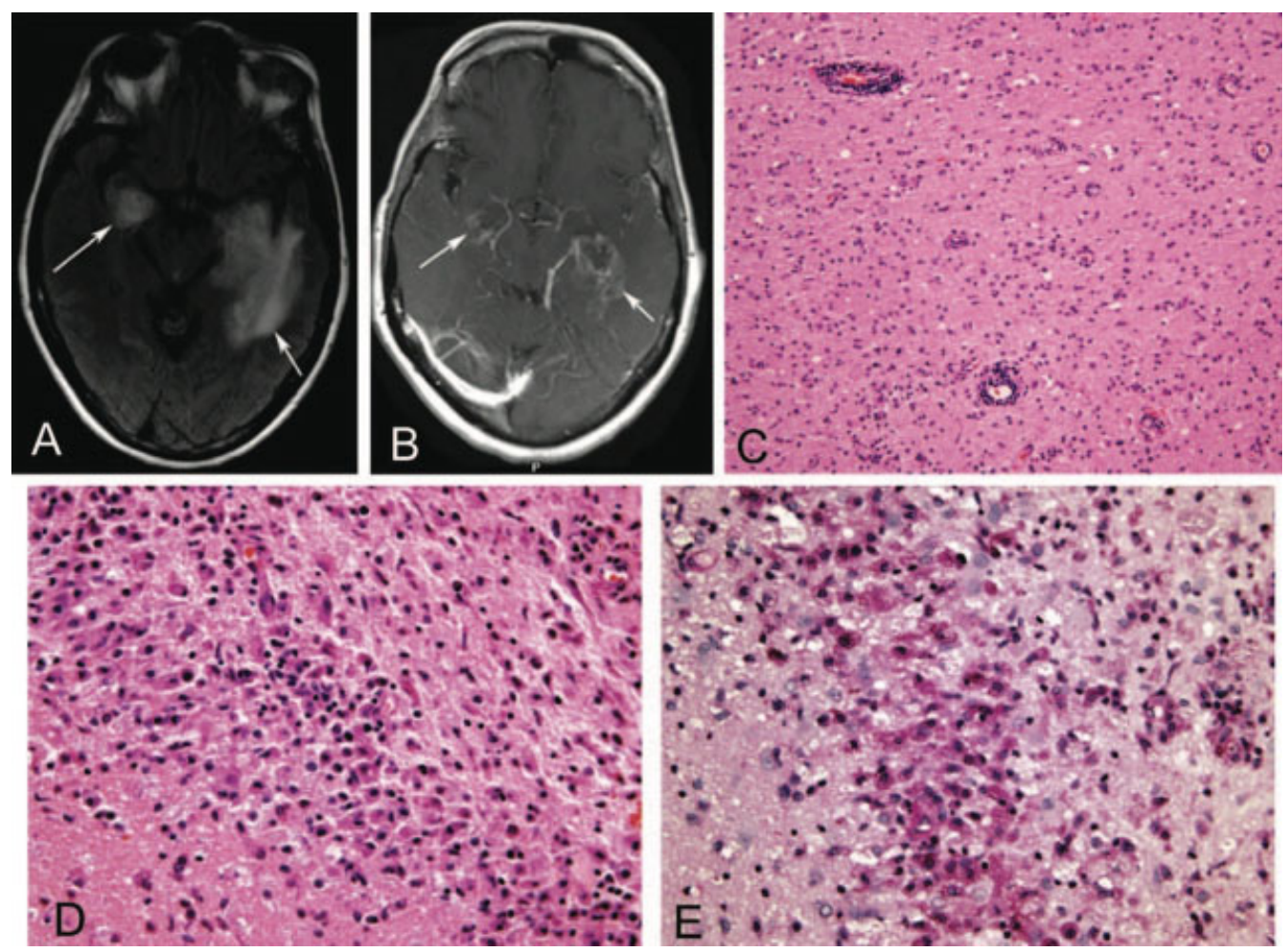

Fig. 3 (A) Axial fluid-attenuated inversion recovery magnetic resonance imaging (MRI) demonstrating bilateral hyperintense temporal lobe lesions (arrows), left greater than right, involving cortex and subjacent white matter. (B) Axial T1-weighted postcontrast MRI demonstrating bilateral hypointense temporal lobe lesions (arrows) with peripheral enhancement and some prominent surrounding vessels. (C) Perivascular lymphohistiocytic inflammatory infiltrate (hematoxylin-eosin, original magnification 200). (D) Macrophages with pale eosinophilic, foamy cytoplasm (hematoxylin-eosin, original magnification 400). (E) Brightly periodic acid-Schiff-positive intracellular organisms within macrophages (original magni fication 400). Pathologic diagnosis: Whipple disease. 

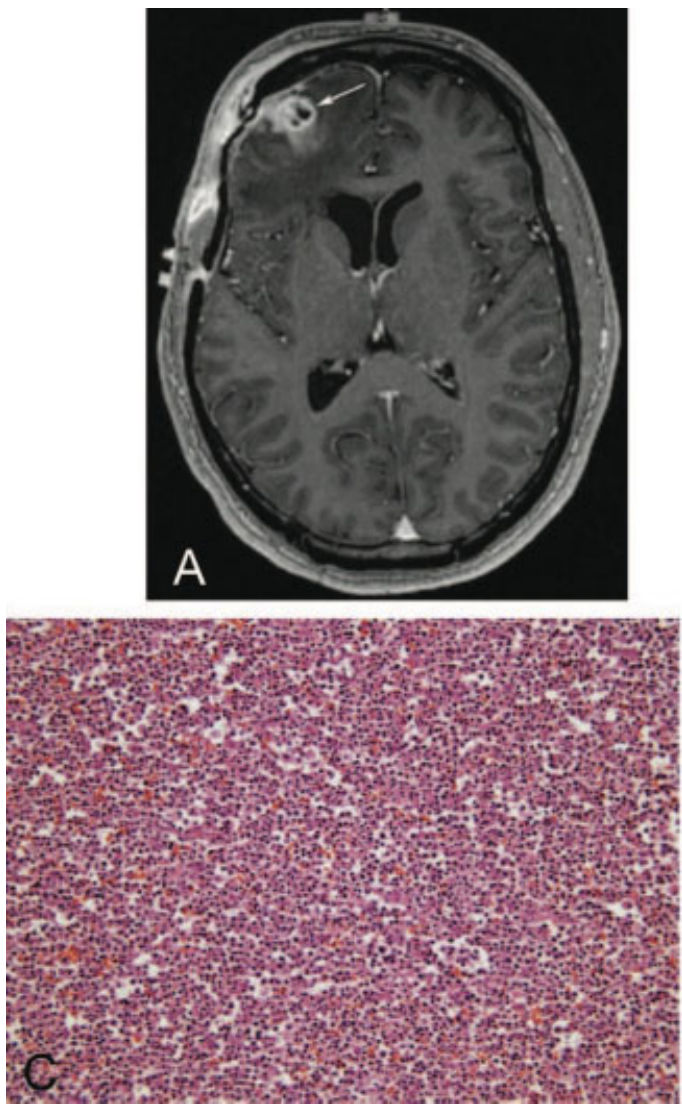
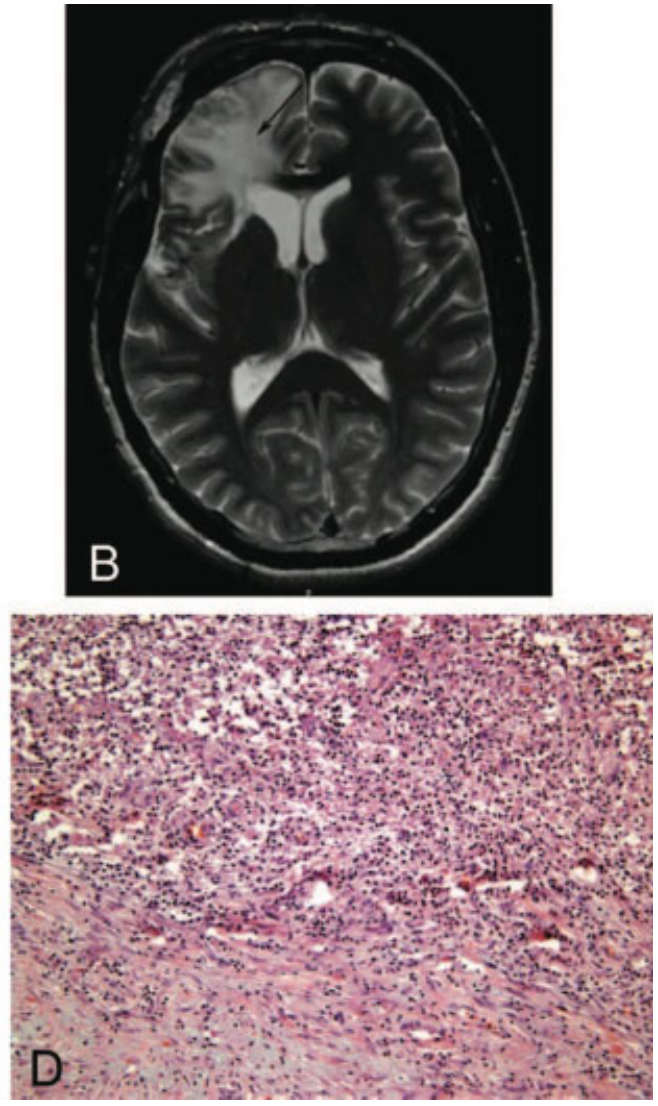

Fig. 4 (A) Axial postcontrast T1-weighted magnetic resonance imaging (MRI) demonstrating a peripherally enhancing lesion (arrow) within right frontal lobe, with cortical extension. (B) Axial T2-weighted MRI demonstrating marked T2 hyperintense perilesional edema (arrow) typical for a bacterial infection. (C) Abscess containing dense collections of neutrophils (hematoxylin-eosin, original magnification 200). (D) Edge of abscess is composed of a fibroinflammatory capsule (hematoxylin-eosin, original magnification 200). Pathologic diagnosis: bacterial abscess.
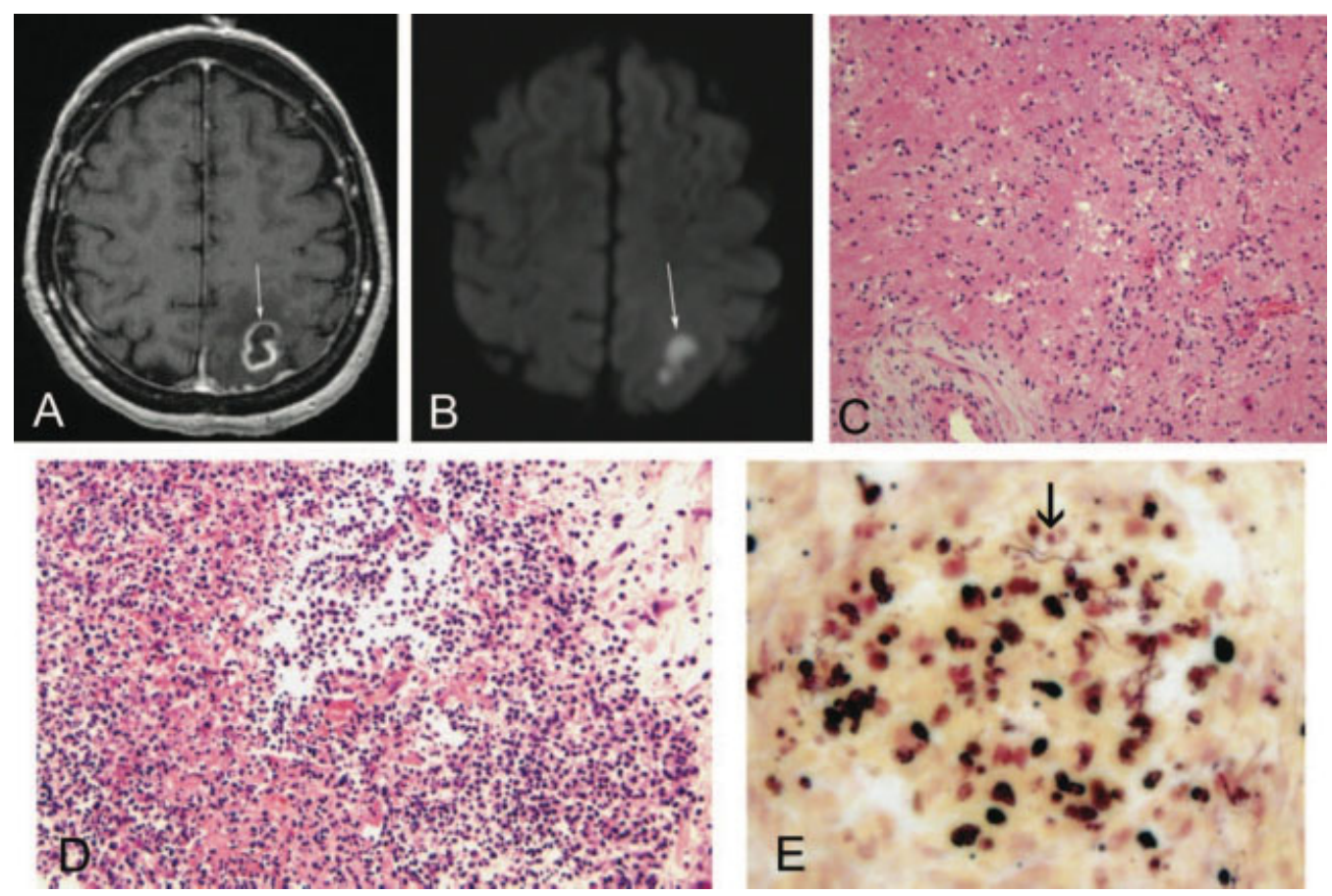

Fig. 5 (A) Axial postcontrast T1-weighted magnetic resonance imaging demonstrates a ring-enhancing lesion (arrow) within the left parietal white matter with central hypointensity and surrounding edema. (B) Axial diffusion-weighted imaging.The lesion (arrow) demonstrateshyperintensity on diffusion imaging. (C) Gliotic brain tissue with mixed inflammatory infiltrate (hematoxylin-eosin, original magnification 200). (D) Center of lesion contains neutrophilic abscess (hematoxylin-eosin, original magnification 200). (E) Tissue Gram stain reveals fine, filamentous gram-positive bacteria within abscess (arrow) (Brown-Hopps Gram stain, original magnification 1000). Pathologic diagnosis: nocardiosis. 

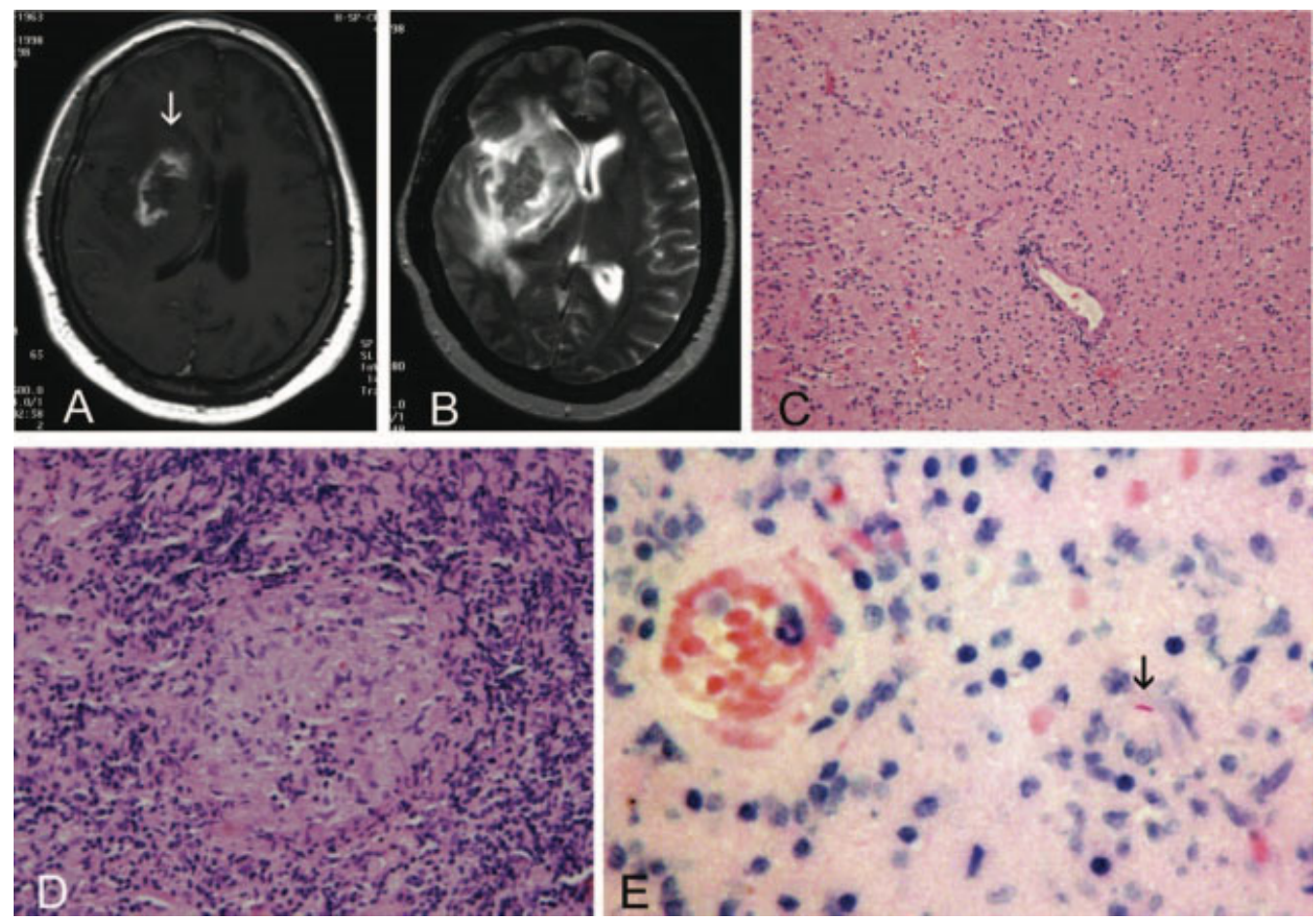

Fig. 6 (A) Axial postcontrast T1-weighted magnetic resonance imaging (MRI) scan demonstrating a right basal ganglia lesion (arrow) with irregular peripheral enhancement with midline shift and surrounding edema. (B) Axial T2-weighted MRI demonstrating heterogeneous signal intensity with central areas of low T2 signal and marked surrounding edema. (C) Gliosis and chronic inflammation (hematoxylin-eosin, original magnification 200). (D) Granuloma with surrounding intense chronic inflammatory infiltrate (hematoxylin-eosin, original magnification200). (E) Rare pink-stained acid-fast bacilli within the lesion (arrow) (Kinyoun acid-fast stain, original magnification 1000). Pathologic diagnosis: tuberculoma.
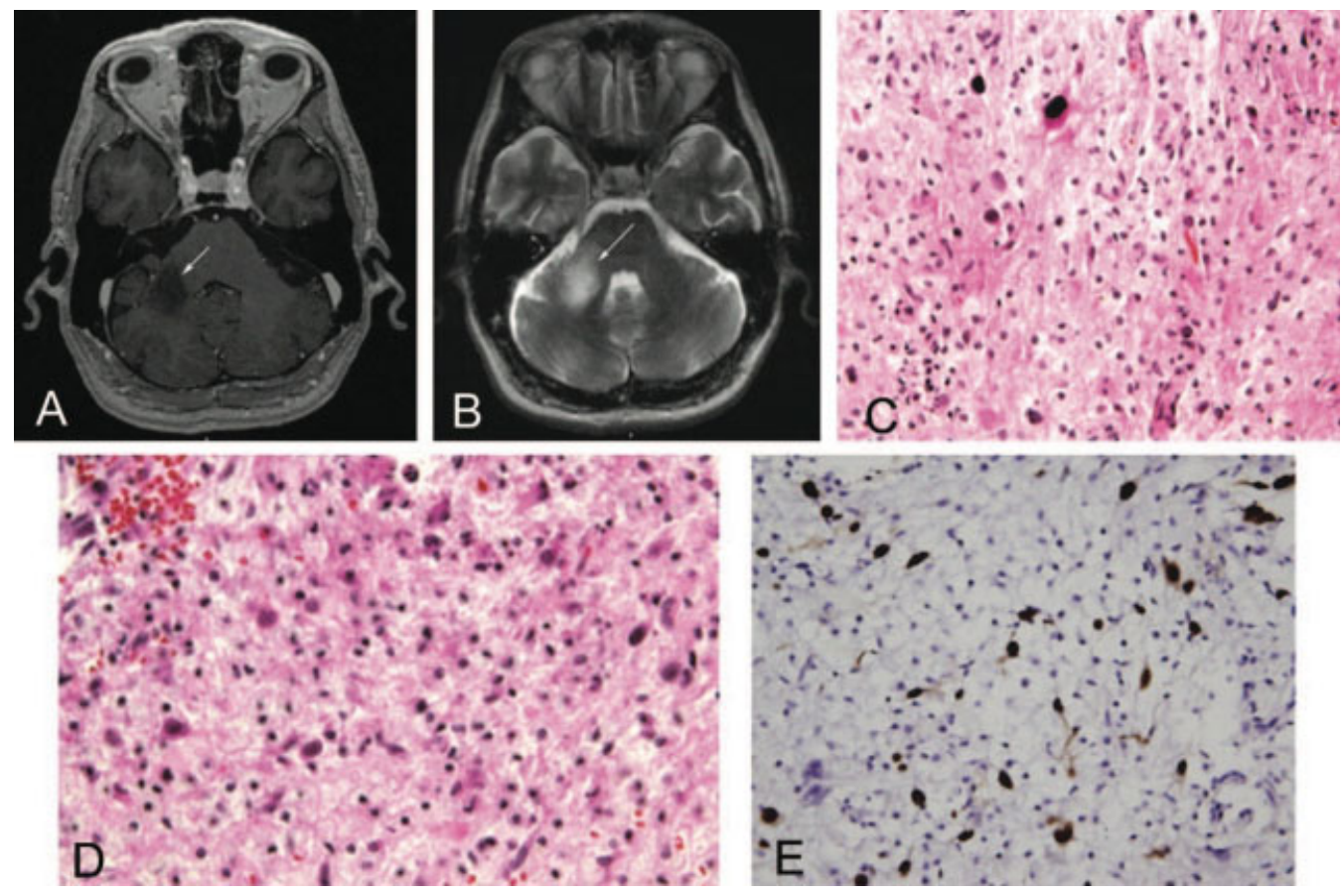

Fig. 7 (A) Axial postcontrast T1-weighted magnetic resonance imaging (MRI) revealing hypointense, nonenhancing lesion within the right middle cerebellar peduncle (arrow). (B) Axial T2-weighted MRI demonstrating T2 hyperintense lesion within the right middle cerebellar peduncle (arrow). (C) White matter pallor with mild chronic inflammation and enlarged, hyperchromatic oligodendroglial nuclei (hematoxylin-eosin, original magnification 400). (D) Enlarged, bizarre astrocytes, with collections of foamy histiocytes (hematoxylin-eosin, original magnification 400). (E) Enlarged progressive multifocal leukoencephalopathy-infected cells are MIB1 ( $\mathrm{K}_{\mathrm{i}}-67$ ) immunopositive (original magnification 400). Pathologic diagnosis: progressive multifocal leukoencephalopathy. 
affect both immunocompromised patients and immunocompetent patients. Radiologically, abscesses can be confused with intracranial tumors. There are several reported cases transplant patients or patients with autoimmune diseases being treated with corticosteroids, brain abscesses which developed that simulate tumors. Histologically, nocardiosis appears as a necrotic injury and acute inflammation. Treatment consists of antibiotics and surgical drainage possible (-Fig. 5). ${ }^{16,17}$

\section{Tuberculoma}

Cerebral tuberculomas may present nodular or ring enhancement in MRI images, similar to a primary or metastatic tumor. When present in the brain, areas of caseous necrosis may correlate with isointense areas or those of mixed intensity on T1-weighted images. The onset of cerebral tuberculomas in MR imaging varies with the age of the lesion. In T2-weighted imaging, immature tuberculomas appear as multiple small isointense or hypointense areas surrounded by hyperintense edema. Mature tuberculomas, on the other hand, are heterogeneous, and can be isointense or hypointense throughout the lesion with ring enhancement visible in the post-contrast $\mathrm{T} 1{ }^{7}$ A magnetic resonance spectroscopy (MRS), generally inconclusive, does not help to distinguish the condition of a neoplasm. Histological appearance of a tuberculoma is characteristic, with granulomatous inflammation, caseous necrosis, and calcification. The pos- sibility of lesion biopsy becomes important for diagnosis because the contribution in distinguishing a tuberculoma with a brain tumor. Treatment for tuberculoma consists of antibiotic therapy and possible surgical intervention. (-Fig. 6). ${ }^{8}$

\section{Progressive Multifocal Leukoencephalopathy (PML)}

The progressive multifocal leukoencephalopathy (PML) is a rare infectious disease classically associated with immunosuppressed individuals. PML is caused by reactivation of a latent virus belonging to the polyomavirus genus. Typically, patients with progressive multifocal leukoencephalopathy present weakness, hemianopia or quadrantanopsia, and cognitive abnormalities. Radiologically, the lesions are usually large and affect the subcortical white substance without mass effect. ${ }^{18}$ The most frequent location is in the parietal lobe, but can also be seen in the occipital lobe, corpus callosum, and thalamus. Some lesions have internal necrosis and the biopsy allows the pathologist to check areas of demyelination and oligodendrocyte with hyperchromatic nuclei. Finally, immunohistochemistry detects the viral capsid protein (-Fig. 7). ${ }^{19,20}$

\section{Neurocysticercosis}

Neurocysticercosis develops as the larval form of Taenia solium is implanted in the subject's brain and causes an inflammatory and granulomatous reaction. It is
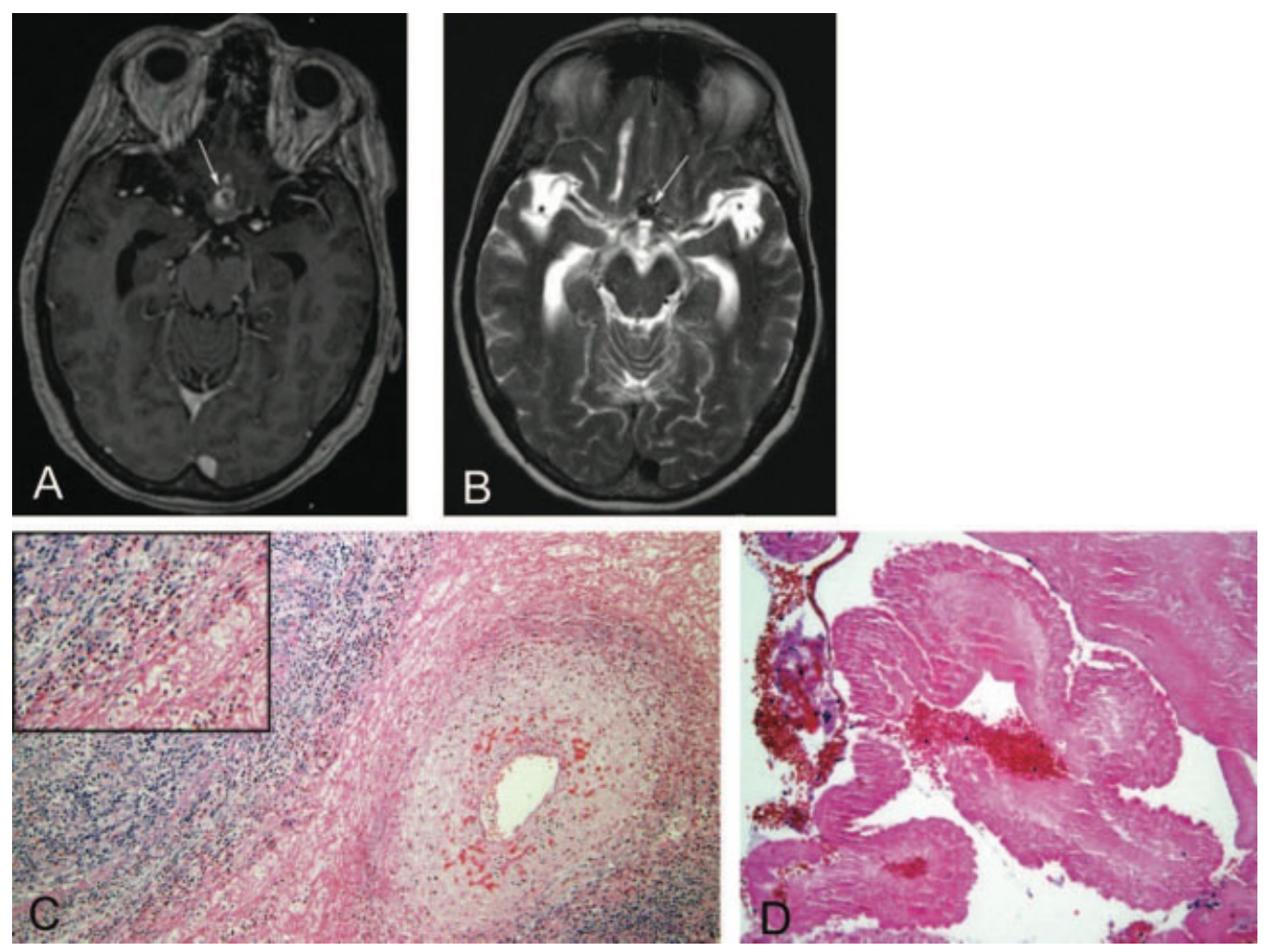

Fig. 8 (A) Axial postcontrast T1-weighted magnetic resonance imaging (MRI) demonstrates suprasellar heterogeneous peripherally ringenhancing lesion (arrow) near the anterior communicating artery. (B) Axial T2-weighted MRI demonstrates a T2 hypointense rounded suprasellar lesion (arrow). (C) Thick-walled vessel with adjacent mixed chronic inflammatory infiltrate (hematoxylin-eosin, original magnification 100). Inset, The infiltrate contains numerous eosinophils. (D) Degenerated eosinophilic capsule of cysticercus, with serrated surface (hematoxylin-eosin, original magnification 200). Pathologic diagnosis: cysticercosis. 
considered the most common cause of acquired seizures worldwide. While epilepsy is the most common symptom, other symptoms include severe headache, meningitis, obstructive hydrocephalus, and cognitive problems. The radiological diagnosis is usually straightforward, although appearance varies according to the stage of the parasite cycle and the age of the lesion. The injury may occur as a single cyst or multiple cysts in the brain that undergo calcification, the latter representing dead larvae. When the larvae invade the brain, they appear as small swollen cysts and subsequently become larger lesions or nodules. ${ }^{7}$ Over time, the larvae die, undergo calcification, producing an inflammatory response around the cyst and contributing to the onset of an annular capsule. Unlike what occurs with pyogenic abscesses, cysts are similar in strength to the cerebrospinal fluid. The lesions rarely exceed $20 \mathrm{~mm}$ in diameter and a useful finding is the presence of the scolex within the cyst (the scolex is typically hyperintense on T1 sequences). Solitary lesions are difficult to distinguish from cancer due to surrounding edema and enhancement of the cyst, and may be confused with a radiologically defined glioblastoma multiforme. Treatment consists of administering anti-parasitic drugs and surgical removal, in cases where there is compression of important structures (-Fig. 8). ${ }^{8,21}$

\section{Demyelination}

Pseudotumoral features, also called tumefactive demyelinating plaques, are well-described in the literature. Multiple sclerosis and other demyelinating diseases, such as Shildeŕs disease and acute disseminated encephalomyelitis, may manifest as tumefactive or pseudotumoral lesions. The presence of complete solitary demyelinating lesions result in Challenge of differentiation between brain tumors, such as glioma. ${ }^{22,23}$ Moreover, When the demyelinating lesions have a marked inflammatory component, they may be confused with primary central nervous system, like lymphoma. The characteristics that favor a demyelinating injury include apparent lack of mass effect, and vasogenic edema present (-Fig. 9). ${ }^{24,25}$

\section{Vascular Diseases}

\section{Infarct}

Cases in which high-grade gliomas mimic infarcts in contrast enhancement due to the mass effects are documented in the
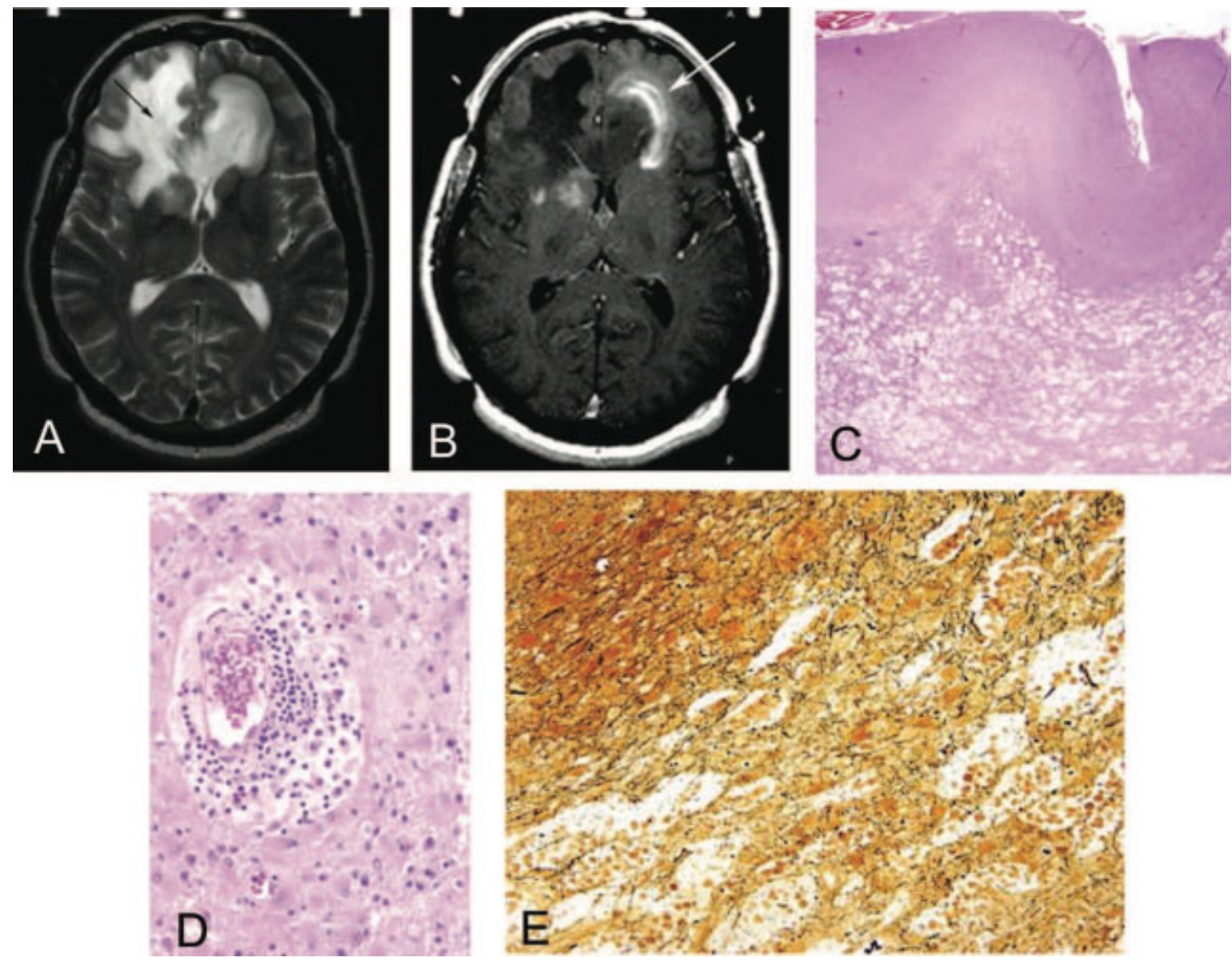

Fig. 9 (A) Axial T2-weighted magnetic resonance imaging (MRI) demonstrating a hyperintense bifrontal butterfly-shaped lesion (arrow) extending across the genu of the corpus callosum. (B) Axial postcontrast T1-weighted MRI demonstrates peripheral enhancement surrounding the lesion, in the form of an open ring (arrow), an imaging sign suggestive of a tumefactive demyelinating lesion. (C) Extensive white matter vacuolation with preservation of the overlying cortex (hematoxylin-eosin, original magnification 40). (D) Perivascular chronic inflammation with surrounding lipid-laden macrophages and gliosis (hematoxylin-eosin, original magnification 400). (E) Relative preservation of axons (stained black) in areas of demyelination (Bielschowsky stain, original magnification 200). Pathologic diagnosis: tumefactive demyelinating lesion. 
literature. The medical practice of repeat images like MRI perfusions, in a short time, could help the distinction of a cerebrovascular accident (CVA) and brain tumor. In most cases, the diagnosis of ischemic stroke / heart attack is not problematic. The clinical history of a sudden onset of neurological symptoms and signs, in combination with typical radiological findings, usually leads to the correct diagnosis. Confounding factors in the diagnosis of ischemic stroke that are more suggestive of a brain tumor include an atypical presentation of neurological symptoms (slow evolution) and a bad brain injury defined in images associated with mass effect, as well as radiological similarity to glioma. An understanding of the cerebral arterial vasculature is essential to reach the correct diagnosis (-Fig. 10). ${ }^{26}$
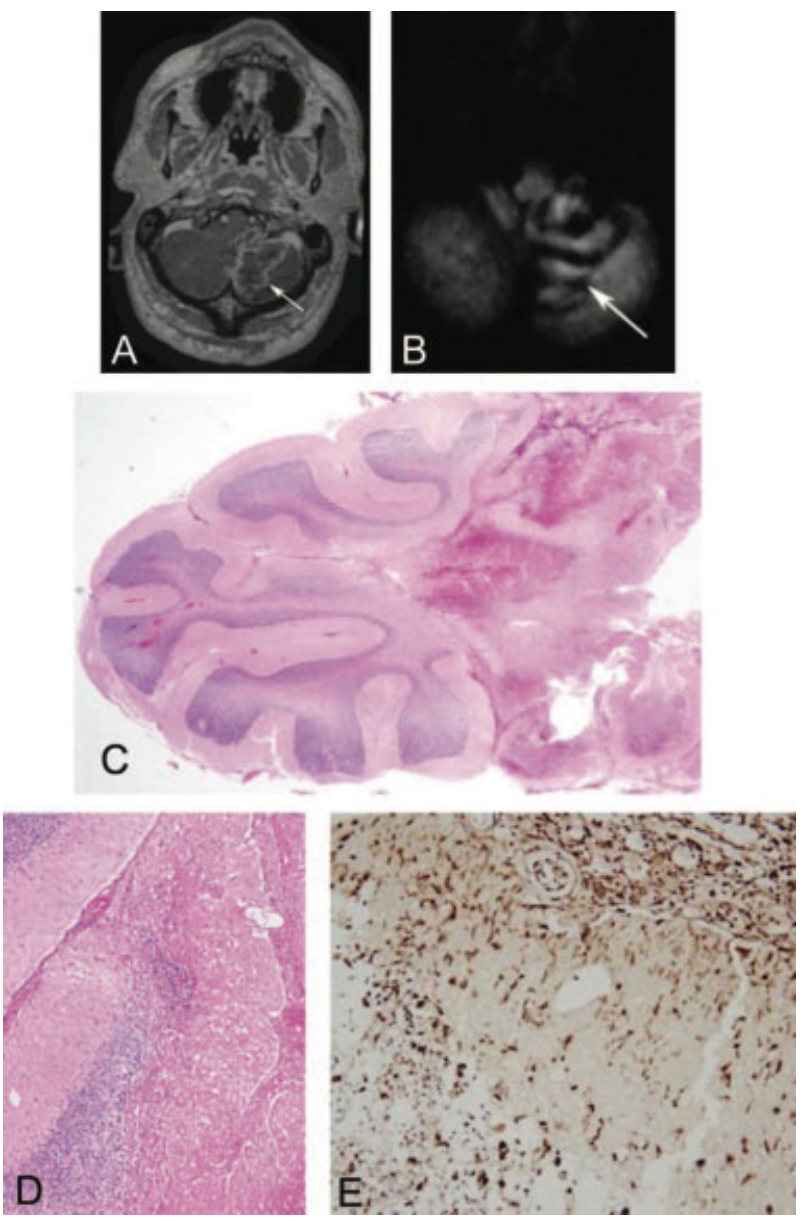

Fig. 10 (A) Axial postcontrast T1-weighted magnetic resonance imaging demonstrating abnormal gyriform enhancement involving the bilateral paramedian cerebellar hemispheres, left greater than right (arrow), with mass effect and edema. (B) Axial diffusionweighted imaging demonstrates gyriform hyperintensity of the cerebellar folia (arrow), mimicking the appearance of LhermitteDuclos disease. (C) Sharply demarcated area of cortical necrosis at right of field, extending to underlying white matter (hematoxylineosin, original magnification 12). (D) Eosinophilic, demarcated area of cortical necrosis seen at right of field (hematoxylin-eosin, original magnification 200). (E) Numerous KP-1 immunopositive macrophages and microglia within infarct (original magnification 400). Pathologic diagnosis: subacute infarct.

\section{Vasculitis}

The clinical presentation and radiographic findings do not provide unequivocal evidence in the diagnosis of vasculitis. Patients with sudden neurological focal deficit and ring-enhancing lesions located in the white matter creates a situation where the diagnosis of high-grade glioma becomes probable. In reality, there are relatively few cases of such conditions reported in the literature. However, other imaging techniques, such as magnetic resonance angiography, may be useful in the differential diagnosis. ${ }^{26}$ Behcet's disease (systemic inflammatory disease that can cause CNS vasculitis) can manifest in ambiguously in radiological images, because the images may appear as a solitary pseudotumor in one hemisphere, with low attenuation on the T1-weighted MRI and extensive hyperintense fluid. However, this scenario is also rare, as Behcet's disease generally presents as multiple hyperintense lesions in T2. The MR spectroscopy can be useful to distinguish a vasculitis lesion from a neoplastic one. There is a case report of lymphocytic vasculitis simulating multifocal lesions in the right cerebral hemisphere, with significant vasogenic edema associated with injury. ${ }^{27}$ Radiologically, the lesions mimicked a multifocal glioma. However, the MRS pattern was more consistent with an inflammatory process (no elevated choline peak, marked elevation of glutamate/glutamine metabolites) rather than an aggressive neoplasm. The diagnosis was confirmed by craniotomy and excisional biopsy (-Fig. 11). ${ }^{28}$

\section{Traumatic}

\section{Chronic Subdural Hematoma (CSH)}

Chronic subdural hematoma (CSH) is a blood collection of chronic evolution, located between the dura and arachnoid. It affects mainly males over sixty years old. Accidental fall has been reported in most patients and their clinical picture is quite varied and can mimic other disease processes. The means for effective diagnosis has been computed tomography of the skull and its treatment of choice has been primarily surgical. In computed tomography, CSH is expressed as a laminar, dynamic injury, and its appearance depends on the time of evolution. Immediately after the hematoma, hemorrhage appears hyperdense. During the following weeks, there is intense fibrinolysis and the hematoma becomes isodense. After about a month, the picture becomes hypodense due to liquefied blood inside the hematoma. Other diagnoses that have been made, is higroma (-Fig. 12).

\section{Amyloidosis}

\section{Amyloidoma}

The challenges in the differential diagnosis related to the amyloid deposition are significant when there is no evidence of any systemic disease associated with amyloid deposition. There are several reports of such in the central nervous system. The most frequent presentation is as intracranial cerebral amyloid angiopathy, or as deposits 

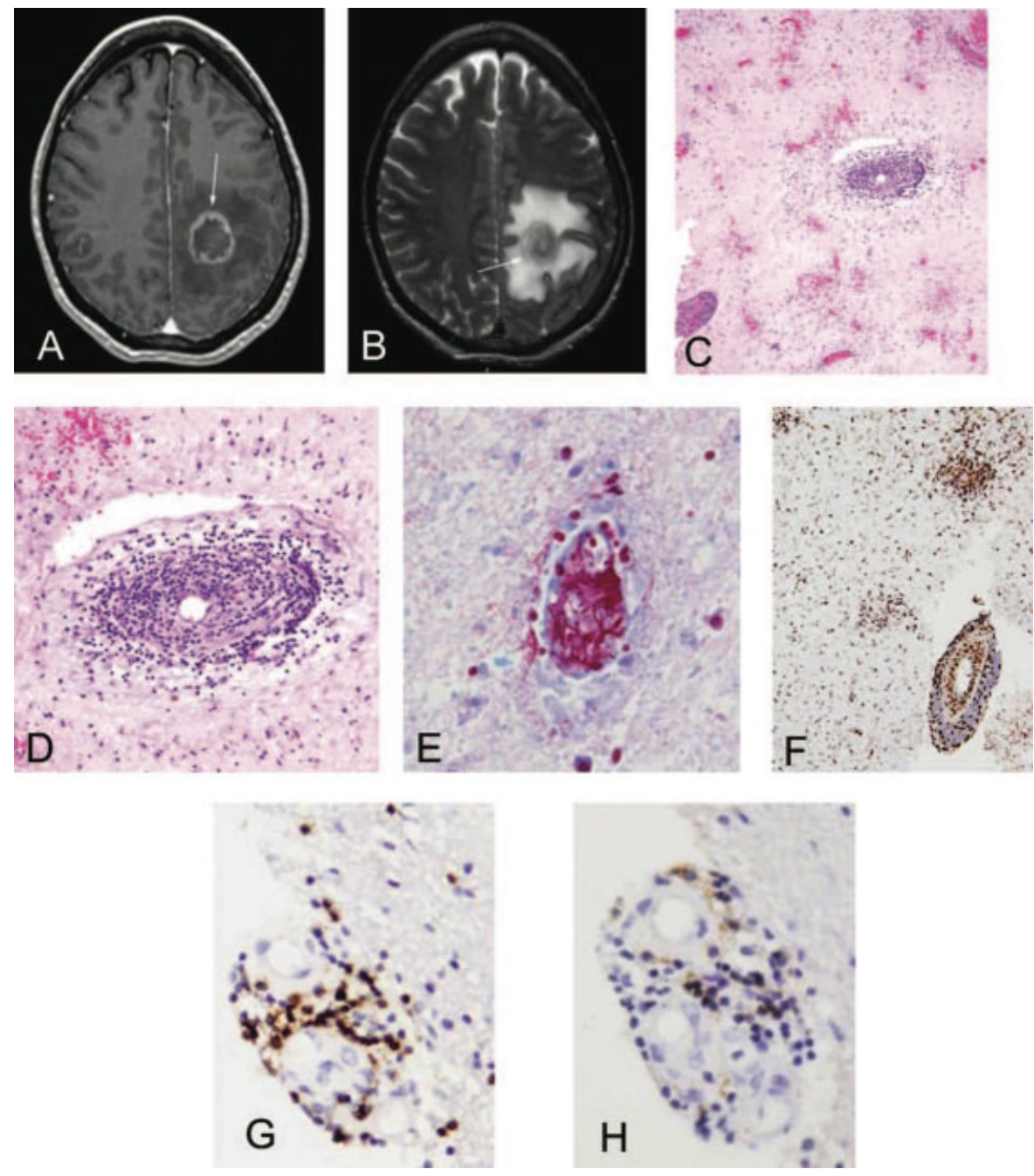

Fig. 11 (A) Axial postcontrast T1-weighted magnetic resonance imaging (MRI) reveals a centrally hypointense deep left parietal lobe mass lesion (arrow) with a thickened, irregular enhancing rim. (B) Axial T2-weighted MRI demonstrates a rounded T2 hypointense left parietal lesion (arrow) with marked surrounding edema. (C) Prominent perivascular inflammatory infiltrate (hematoxylin-eosin, original magnification 100). (D) Fibrinoid necrosis of vessel wall (hematoxylin-eosin, original magnification 400). (E) The fibrinoid necrosis is highlighted bright red by an azocarmine stain (original magnification 400). (F) Perivascular histiocytes within the infiltrate are immunopositive for CD68 (KP-1) (original magnification 200). (G) Perivascular B cells are highlighted by the CD20 immunostain (original magnification 400). (H) Perivascular T cells are highlighted by the CD3 immunostain (original magnification 400). Pathologic diagnosis: vasculitis.
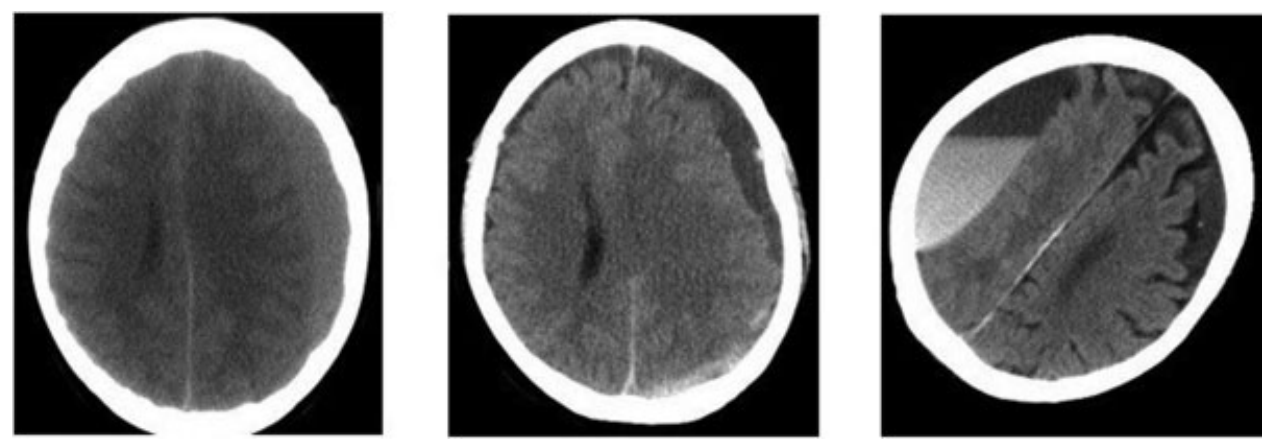

Fig. 12 Chronic subdural hematoma, higroma subdural, subdural hematoma acute-chronic, respectively 

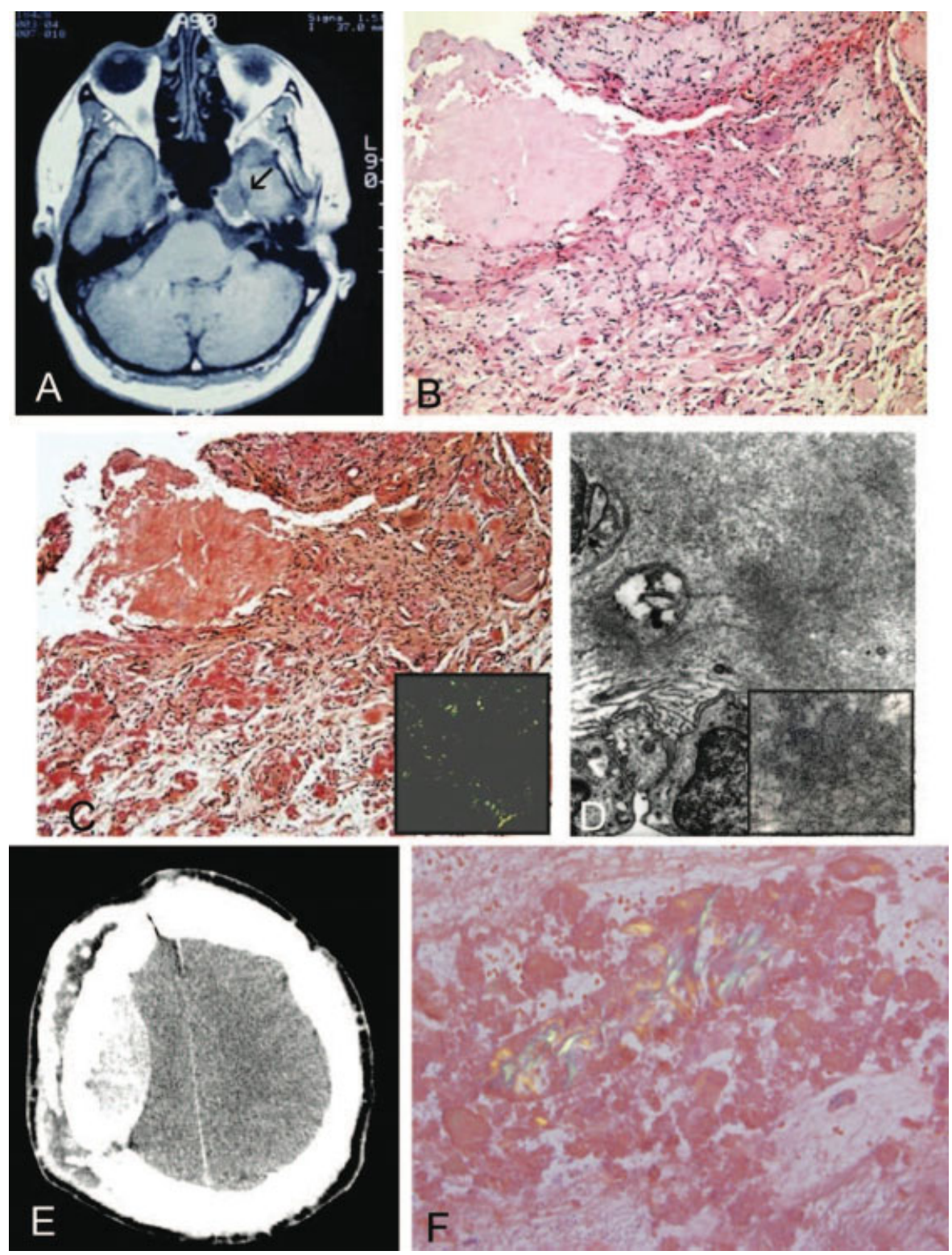

Fig. 13 (A) Axial postcontrast T1-weighted magnetic resonance imaging (MRI) demonstrating a mildly hypointense mass (arrow) centered at left Meckel cave at the expected location of the trigeminal/gasserian ganglion. (B) Homogeneous eosinophilic deposits are present within lesion (hematoxylin-eosin, original magnification 100). (C) The deposits are stained orange-red (Congo red stain, original magnification 100). Inset, Deposits demonstrate apple green birefringence under polarized light (Congo red stain and polarized light, original magnification 100). (D) and inset, Electron microscopy reveals haphazard arrangement of 6-m fibrils, typical for amyloid. (E) Axial computed tomography bone window shows a hyperdense biconvex-shaped lesion involving the right frontoparietal calvarium causing mass effect on the right cerebral hemisphere. (F) Congophilic deposits have apple green birefringence (Congo red stain and polarized light, original magnification 400). Pathologic diagnosis: amyloidoma.

in senile plaques in patients with Alzheimer's disease. ${ }^{29}$ Amyloidoma is significantly less frequent. Moreover, the clinical and radiological presentation of amyloid deposits as intracranial tumors is rare. Nonetheless, there are reports of tumor masses in the cerebral hemispheres in patients aged 28-60 years, including the temporal lobes, occipital, and the cerebellopontine angle. Generally, they appear as masses of supratentorial white matter, with little or no mass effect (- Fig. 13). ${ }^{30,31}$

\section{latrogenic}

\section{Necrosis Radiation}

The distinction between radiation necrosis and glioma recurrence can be difficult. In cases of high-grade glioma, both lesions are likely to be present simultaneously. In such cases, the challenge is to determine the predominant injury (necrosis radiation or neoplasia), as this may interfere with treatment planning. A further increase the contrast of the 

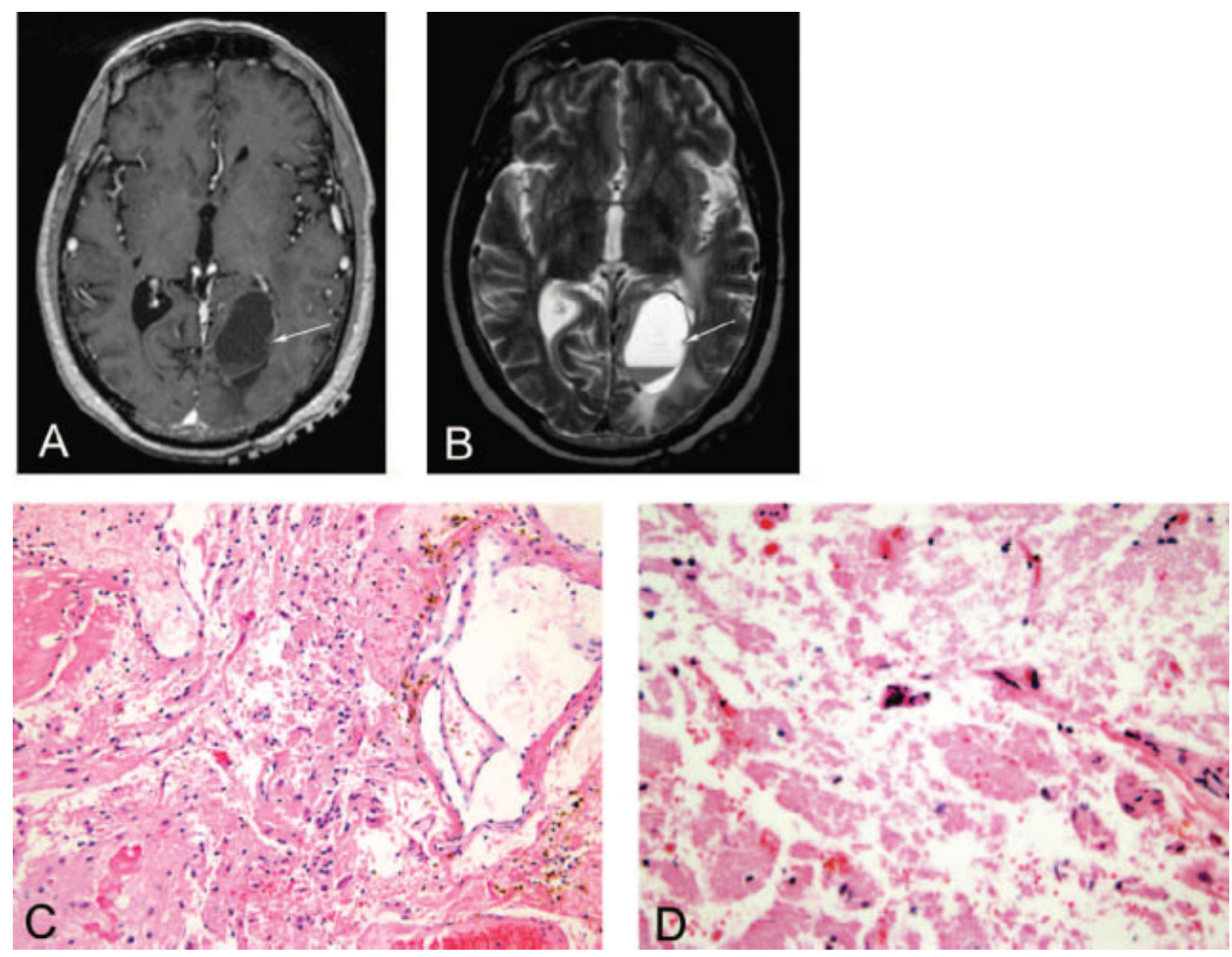

Fig. 14 A, Axial postcontrast T1-weighted magnetic resonance imaging (MRI) demonstrates a well-circumscribed mass (arrow) within the left posterior parietooccipital region with thin peripheral enhancement. B, Axial T2-weighted MRI reveals a hyperintense partially cystic lesion (arrow) with an internal fluid-fluid level. C, There is parenchymal necrosis with hemosiderin deposits and dilated vascular channels (hematoxylineosin, original magnification 200). D, Necrosis and hemosiderin deposits (hematoxylin-eosin, original magnification 400). Pathologic diagnosis: radiation necrosis.

secondary irradiation may be seen within a variable period after administration of radiation therapy. Obviously, to obtain a history need is critical in such cases. A suggestive radiological data of radiation necrosis is the irregular appearance of hypointense lesion diffusion weighted image. Some key features on MRI of radiation necrosis associated with recurrent glioma, including late contrast, vasogenic edema, and mass effect ( - Fig. 14). ${ }^{7,32,33}$

\section{Tumors}

There are several tumors that can express in hypodense form in computed tomography, such as astrocytoma, glioma, ependymoma, haemangioblastoma, gliomatosis, and brain metastases. Include non-neoplastic cranial cysts as hygroma, hypertensive collection formed mainly by cerebrospinal fluid (CSF) that, for the most part, is related to traumatic brain injury and form due to injury of the arachnoid with subsequent leakage of spinal fluid to the subdural space. In these cases, the treatment of choice will depend on the tumor staging as well as its characteristics, such as size and location. Nevertheless, surgical intervention is required in most cases, and can be associated with chemotherapy and radiotherapy (-Fig. 15) ${ }^{30,31}$

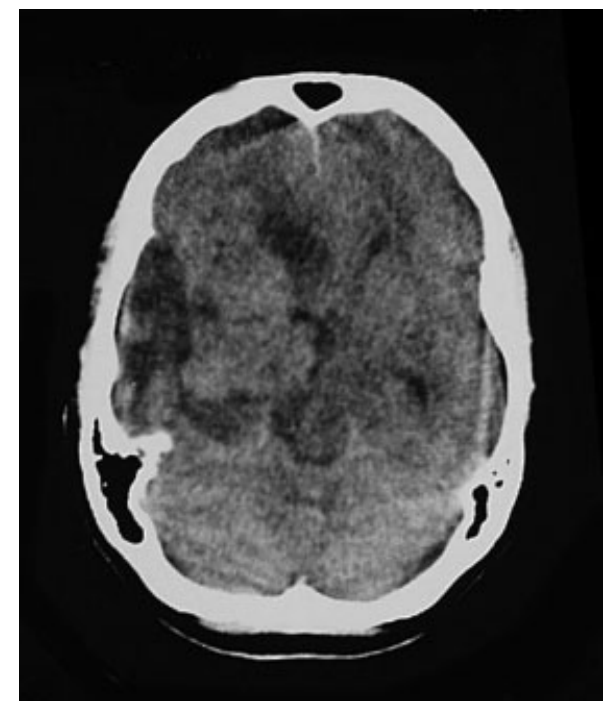

Fig. 15 Glioblastoma multiforme. Large lesion in cerebral hemisphere $\mathrm{D}$, reaching the temporal lobe, insula, basal ganglia, and thalamus. 

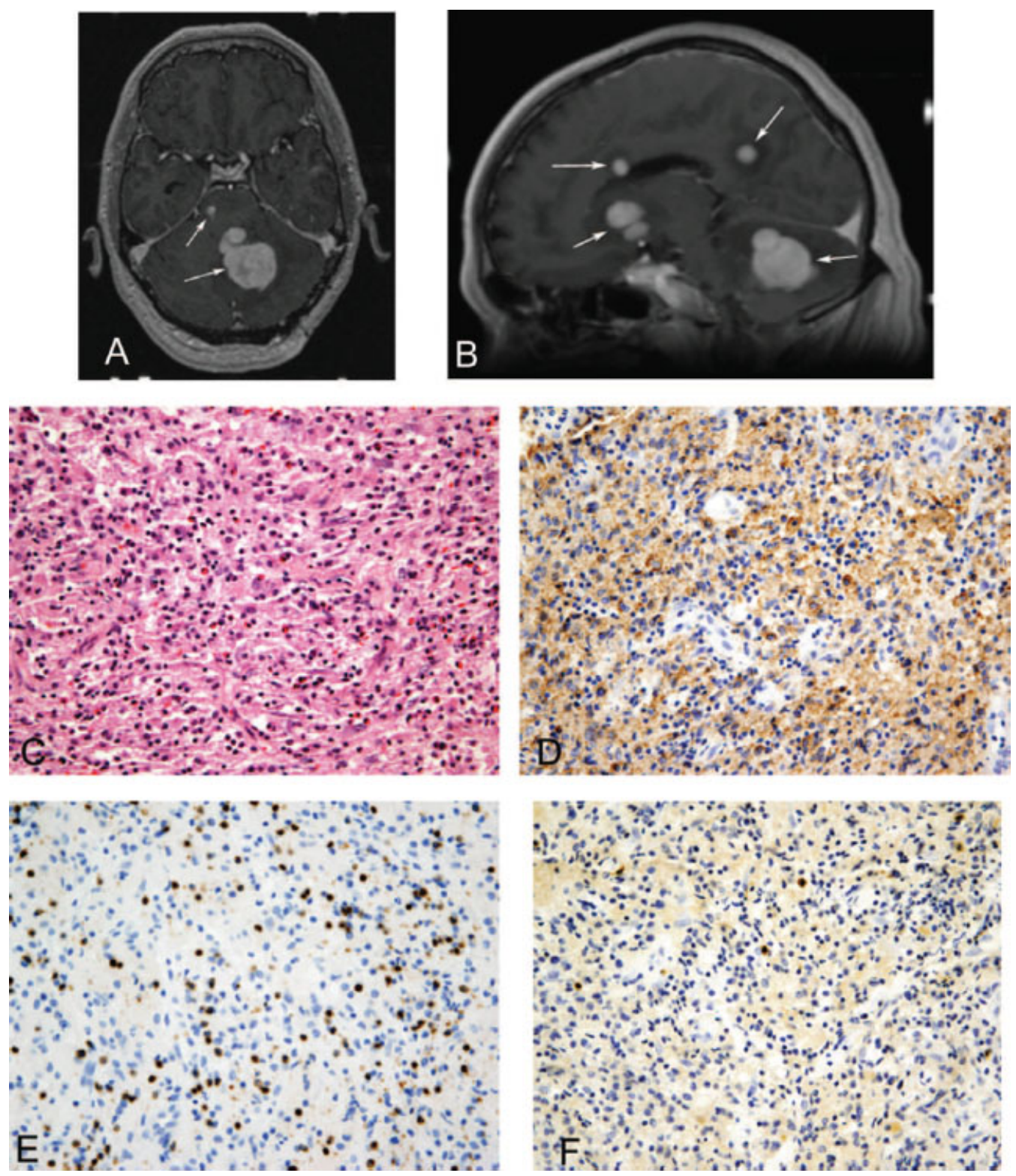

Fig. 16 A, Axial postcontrast T1-weighted magnetic resonance imaging (MRI) demonstrating a homogeneously enhancing left cerebellar mass (lower arrow) with perilesional edema and a second right pontine-enhancing nodule (upper arrow). B, Sagittal postcontrast T1-weighted MRI again reveals the cerebellar lesion (lower arrow) with additional enhancing lesions (upper arrows) within the corpus callosum, posterior cingulate gyrus.

\section{Inflammatory Pseudotumor}

Inflammatory pseudotumors, also known as inflammatory myofibroblastic tumors, may involve any organ system. In the CNS, it most commonly produces a duralbased/ meningeal mass, although it may be intraparenchymal or may occasionally arise from the choroid plexus, producing a hyperdense intraventricular mass on CT imaging. Shah and McClain described a form of inflammatory pseudotumor (plasma cell granuloma) involving the cavernous sinus and middle cranial fossa in a 14-year old girl. On MRI, it was seen to extend into the pterygopalatine and infratemporal fossae producing thickening of the right lateral tentorium and edema of the right temporal lobe. Typically, inflammatory pseudotumor is hypoin- tense on T1-weighted images and markedly hypointense on T2. Because of its polymorphous histologic appearance, ranging from hypocellular connective tissue containing scattered mixed mononuclear inflammatory cells to a proliferation of plump fibroblastic cells with a prominent inflammatory component, it may potentially be confused with a lymphoplasmacyte-rich meningioma or even a fibroblastic meningioma. The radiologic appearance of a dural-based mass may further mislead the pathologist. ${ }^{34}$

The demographics of patients with the 2 lesions are different, however, with most inflammatory pseudotumors (73\%) occurring in those younger than 40 years. 10 There is a distinct male predominance, 10 and most cases in the CNS are 

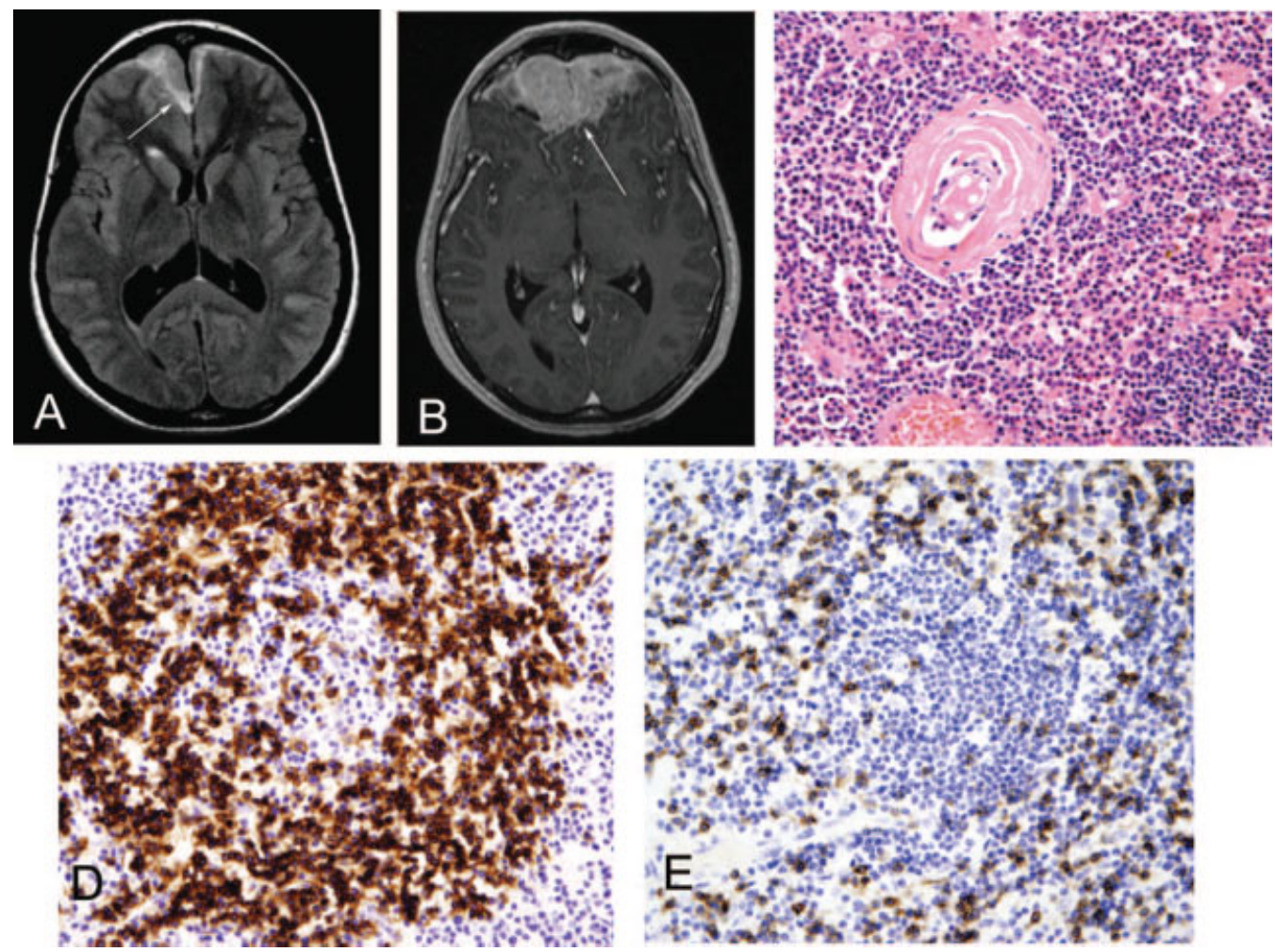

Fig. 17 A, Axial fluid-attentuated inversion recovery magnetic resonance imaging (MRI) demonstrates increased signal intensity bifrontally on either side of the falx (arrow). B, Axial postcontrast T1-weighted MRI shows contrast-enhancing lesion (arrow) along the falx and frontal dura bilaterally. C, A dense lymphocytic infiltrate surrounds hyalinized central vessel (hematoxylin-eosin, original magnification 400). D, The lymphocytic infiltrate is predominantly B cells (CD20 immunostain, original magnification 400). E, There is a minor population of T cells (CD3 immunostain, original magnification 400). Pathologic diagnosis: Castleman disease, hyaline-vascular type.

solitary (82\%). Intraparenchymal heterogeneously enhancing inflammatory pseudotumors may mimic a malignant brain neoplasm (-Fig. 16). ${ }^{35}$

\section{Noninfectious Inflammatory Conditions}

\section{Castleman Disease}

Castleman disease, also known as angiofollicular lymph node hyperplasia, occurs in 2 forms. Most cases are the hyalinevascular type, as in our case, with the typical histologic finding of hyalinized follicular centers with a radial penetrating vessels and prominent interfollicular capillary proliferation. The plasma cell type represents only $5 \%$ to $10 \%$ of cases, and is characterized by large lymphoid follicles separated by sheets of mature plasma cells and less stromal vascularization. ${ }^{36}$

Localized forms of the disease are generally asymptomatic, while the generalized form may present with fever, weight loss, anemia, polyneuropathy, organomegaly, and monoclonal proteinemia, thus resembling a paraneoplastic syndrome. Intracranial Castleman disease is very rare, with 13 cases described in the literature, and in this locality it may mimic a neoplasm, in particular a meningioma. Previously described locations include the hemisphere convexities and adjacent to the falx. As expected with the predominantly cortical location of the lesion, patients presented most commonly with seizures, and focal signs such as right hand clumsiness, left hemiparesis, and incoherent speech. ${ }^{37}$

By CT imaging, the lesions were homogeneously enhancing with perilesional edema. Some demonstrated dural enhancement by MRI, mimicking a meningioma. Angiography of these intracranial cases revealed no vascular blush, in contrast to other sites where there is typically a homogeneous capillary blush from neovascularization. Although most cases occur in adults, there is a single report in an 8-year-old girl. The child presented with sudden onset of partial motor seizures and a left posterior parietal, partially mineralized, contrast-enhancing meningeal mass. The treatment of choice for localized Castleman disease is gross total resection of the lesion. In summary, although it is a rare entity in the CNS, Castleman disease should be considered in the differential diagnosis of intracranial meningeal tumors (-Fig. 17). ${ }^{38}$

\section{Rosai-Dorfman Disease}

Sinus histiocytosis with massive lymphadenopathy, or RosaiDorfman disease, was first described in 1969. It typically presents in children and young adults, and has a mean age of onset of 20.6 years, with bilateral, painless cervical lymphadenopathy. Some patients also have systemic symptoms such as elevated sedimentation rate, fever, leukocytosis, and polyclonal hypergammaglobulinemia. Extranodal involvement also 
occurs in more than $40 \%$ of patients, particularly in the paranasal sinuses, orbit, skin, and upper respiratory tract. Central nervous system involvement is less common, being found in $22 \%$ of patients, and isolated CNS disease is rarer still. Disease of the CNS typically manifests itself in the epidural or subdural compartments, but a suprasellar location has been reported. Patients presenting with or developing cranial involvement have a mean age of 34.9 years, with a male predominance. Some of the usual presentations of intracranial disease include seizures, headache, cranial nerve deficits, hemiparesis, and dysphasia. Imaging reveals single or multiple meningeal-based masses, which are enhancing, with variable surrounding edema, and can appear identical to a meningioma on CT and MRI scan. Associated lytic lesions may be seen in the skull. On surgical resection, the lesion may also grossly be indistinguishable from a meningioma, and so diagnosis will rest with histology. Fortunately, differentiation of sinus histiocytosis with massive lymphadenopathy from meningioma presents no difficulty in most cases, with the possible exception of the lymphoplasmocyte-rich variant of meningioma. ${ }^{39}$

Helpful histologic features include the characteristic palestaining histiocytes with delicate nuclear membranes, exhibiting emperipolesis, that is, intact lymphocytes, neutrophils, and plasma cells within the cytoplasm. Immunohistochemistry is helpful in demonstrating the characteristic S100 protein, CD68, and factor XIIIa-positive histiocytes, which unlike those in Langerhans cell histiocytosis, are negative for CD1a. Because there are as yet only a few reports of intracranial Rosai-Dorfman disease, the ideal treatment for this condition is so far undefined. Surgery has been the treatment of choice. Adjunctive therapy has included chemotherapy, irradiation, and steroids. The effectiveness of steroids in this condition has been describedAnother systemic histiocytic disease that can involve the CNS and produce lesions mimicking a primary brain tumor is Erdheim-Chester disease. ${ }^{40}$

The disease is a non-Langerhans cell histiocytosis and usually affects middle-aged adults, producing osteosclerotic and lipogranulomatous lesions of the long bones and retroperitoneal and pulmonary fibrosis. When there is neurologic involvement, it typically manifests itself as hypothalamic/pituitary dysfunction. A solitary left temporoparietal cortical lesion has been described in a previously healthy 26 -year-old patient who experienced recent
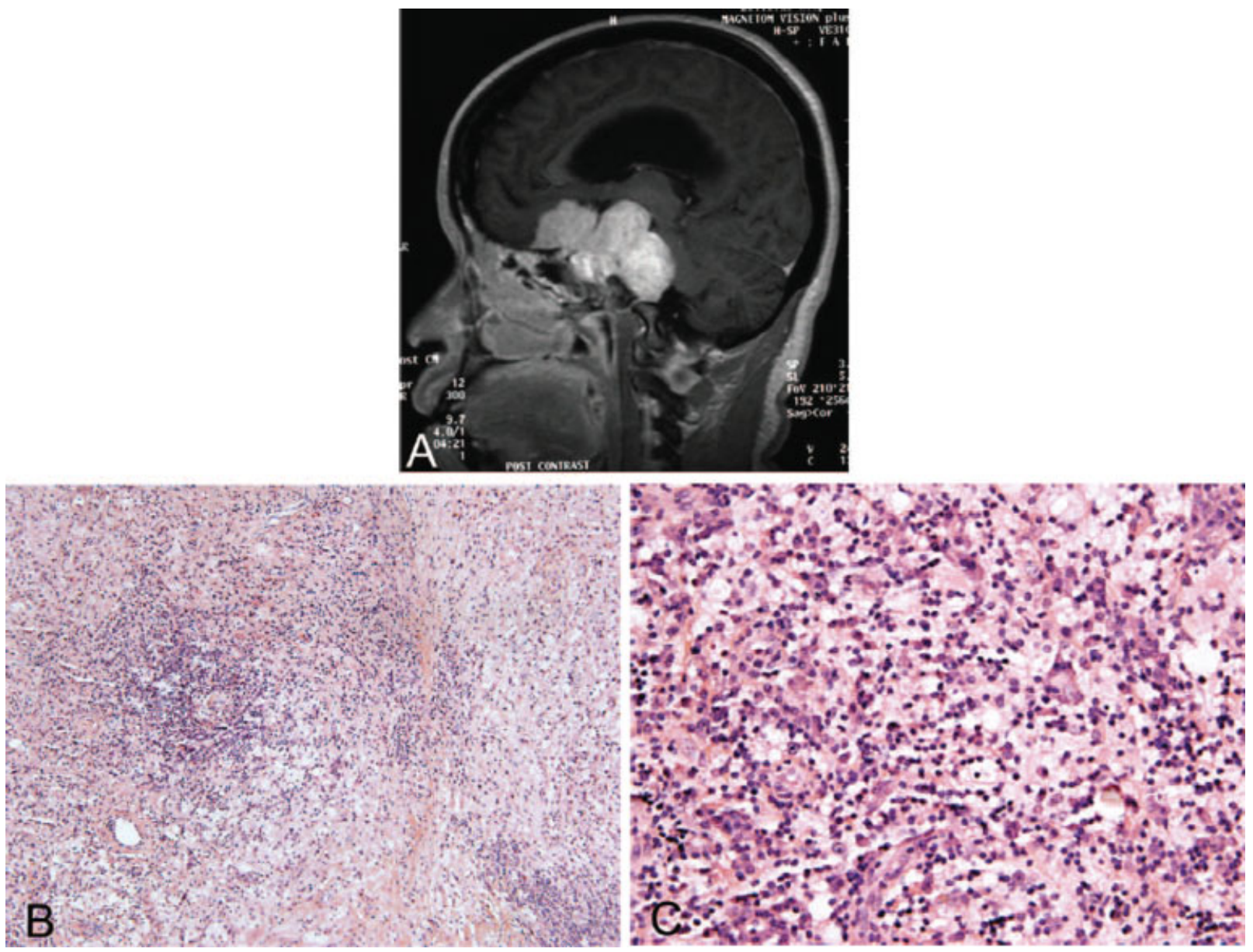

Fig. 18 A, Sagittal postcontrast T1 magnetic resonance imaging shows a trilobed-enhancing central skull base lesion with involvement of the sella and suprasella cistern. B. The resected lesion contains a dense diffuse mixed inflammatory infiltrate (hematoxylin-eosin, original magnification 100). C, Within the infiltrate, there are numerous pale-staining histiocytes and plasma cells (hematoxylin-eosin, original magnification 400). Pathologic diagnosis: Rosai-Dorfman disease. 
Publisher: Thieme; Journal: ABN; Article Type: Original Research Journal ISSN: 0103-5355; Article ID Number: 00320161 Volume Number: 35 ; Issue Number:

\section{Algorithm for diagnosis of brain lesions}

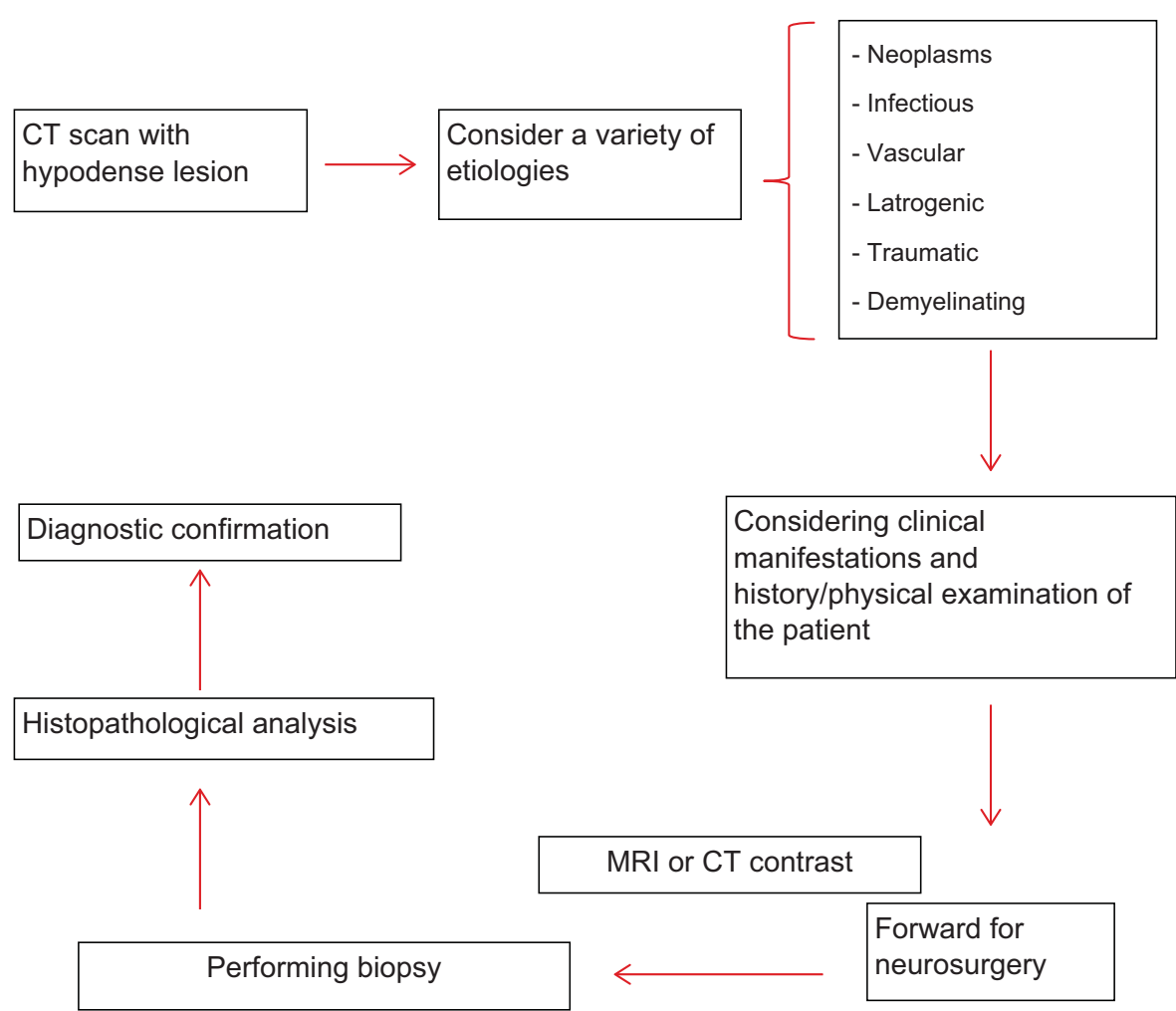

Fig. 19 Algorithm for diagnosis of brain lesions. Abbreviattions: CT, computed tomography; MRI, magnetic resonance image.

onset of seizures. The lesion was solitary, well-demarcated and homogeneously enhancing on MRI examination. It had minimal surrounding edema and no mass effect. Positron emission tomography scan suggested a low-grade neoplasm, such as astrocytoma or pleomorphic xanthoastrocytoma. Intraoperative squash preparations and frozen sections revealed many multinucleate cells with a background of fibrillary astrocytes, and a diagnosis of glial neoplasm was made. On permanent histology, clusters of xanthomatous histiocytic cells were evident, many of which were multinucleate with a wreathlike nuclear arrangement, surrounded by dense gliosis. The histiocytic cells were KP-1 (CD68) immunopositive and negative for CD1a and S100 (in contrast to those seenin Rosai-Dorfman disease or Langerhans cell histiocytosis) (- Fig. 18). ${ }^{41,42}$

\section{Conclusion}

As a possible result of the relatively high percentage of wrong diagnoses neuroradiological, patients with benign tumors, inflammatory lesions or vascular injury may be subjected to unnecessary radiation, chemotherapy, or both. CT is the most used exame, but even RMI make some indistinguishable lesions. Histological diagnosis should be necessary in most cases before starting treatment, since incorrect diagnostic hypotheses are made even, and thus, inappropriate therapeutic regimens may be administered. With the advent of microsurgery and stereotactic biopsy guided by $\mathrm{CT}$, there is little damage, in addition to those in the brain stem, which cannot safely undergo biopsy. High resolution CT, particularly when used in combination with a high dose of contrast and scanning, is a highly sensitive method for the detection of intracranial lesions. However, even with the use of numerous neuroradiological methods, specificity guarantee still requires histological examination in most cases. This paper contributes an algorithm for diagnosis brain hypodense lesions in non-contrast on (-Fig. 19).

\section{References}

1 Alapatt JP, Kutty RK, Gopi PP, Challissery J. Middle and posterior fossa aspergilloma. Surg Neurol 2006;66(1):75-78, discussion 78-79

2 Siddiqui AA, Bashir SH, Ali Shah A, et al. Diagnostic MR imaging features of craniocerebral Aspergillosis of sino-nasal origin in 
immunocompetent patients. Acta Neurochir (Wien) 2006; 148:155-166

3 Okamoto K, Furusawa T, Ishikawa K, Quadery FA, Sasai K, Tokiguchi S. Mimics of brain tumor on neuroimaging: part II. Radiat Med 2004;22:135-142

4 Dubey A, Patwardhan RV, Sampth S, Santosh V, Kolluri S, Nanda A. Intracranial fungal granuloma: analysis of 40 patients and review of the literature. Surg Neurol 2005;63:254-260

5 Dickerman RD, Stevens QE, Schneider SJ. Sudden death secondary to fulminant intracranial aspegillosis in a healthy teenager after posterior fossa surgery: the role of corticosteroids and prophylactic recommendations. J Neurosurg Sci 2004; 48:87-89

6 Cunha BA. Central nervous system infections in the compromised host: a diagnostic approach. Infect Dis Clin North Am 2001; 15:567-590

7 Omuro AM, Leite CC, Mokhtari K, Delattre JY. Pitfalls in the diagnosis of brain tumours. Lancet Neurol 2006;5:937-948

8 Okamoto K, Furusawa T, Ishikawa K, Quadery FA, Sasai K, Tokiguchi S. Mimics of brain tumor on neuroimaging: part I. Radiat Med 2004;22:63-76

9 Tien RD, Chu PK, Hesselink JR, Duberg A, Wiley C. Intracranial cryptococcosis in immunocompromised patients: CT and MR findings in 29 cases. AJNR Am J Neuroradiol 1991;12:283-289

10 Kanaly CW, Selznick LA, Cummings TJ, Adamson DC. Cerebellar cryptococcoma in a patient with undiagnosed sarcoidosis: case report. Neurosurgery 2007;60:E571

11 Panegyres PK, Edis R, Beaman M. Doença de Whipple cerebral primária: caracterização da síndrome clínica e diagnóstico molecular. Q J Med 2006;99:609-623

12 Lohr M, Stenzel W, Plum G, Gross WP, Deckert M, Klug N. Whipple disease confined to the central nervous system presenting as a solitary frontal tumor. Case report. J Neurosurg 2004; 101:336-339

13 Akar Z, Tanriover N, Tuzgen S, et al. Intracerebral Whipple disease: unusual location and bone destruction. Case report. J Neurosurg 2002;97:988-991

14 Bink A, Gaa J, Franz K, et al. Importance of diffusion-weighted imaging in the diagnosis of cystic brain tumors and intracerebral abscesses. Zentralbl Neurochir 2005;66:119-125

15 Tung GA, Evangelista P, Rogg JM, Duncan JA III. Imagem de massas cerebrais: Ressonância magnética ponderada em Difusão. AJR Am J Roentgenol 2001;177:709-712

16 Kilincer C, Hamamcioglu MK, Simsek S, et al. Nocardial brain abscess: review of clinical management. J Clin Neurosci 2006; 13:481-485

17 Ozturk S, Tufan F, Alisir S, et al. A case of isolated Nocardia asteroides brain abscess in a kidney transplant recipient. Transplant Proc 2006;38:3121-3124

18 Thurnher MM, Thurnher SA, Mühlbauer B, et al. Leucoencefalopatia multifocal progressiva: TC e RM. Neurorradiol 1997; 39:611-618

19 Whiteman ML, Pós MJ, Berger JR, Tate LG, Sino MD, Limonte LP. Leucoencefalopatia multifocal progressiva em 47 pacientes soropositivos para o HIV: neuroimagem com correlação clínica e patológica. Radiol 1993;187:233-240

20 Gallia GL, DelValle L, Laine C, Curtis M, Khalili K. Leucoencefalopatia multifocal e linfoma do sistema nervoso central primário. Mol Pathol 2001;54:354-359

21 Rajshekhar V. Severe episodic headache as the sole presenting ictal event in patients with a solitary cysticercus granuloma. Acta Neurol Scand 2000;102:44-46
22 Saindane AM, Cha S, a. Lei M, Xue X, Knopp EA, Zagzag D. Proton MR spectroscopy of tumefactive demyelinating lesions. AJNR Am J Neuroradiol 2002;23:1378-1386

23 Masdeu JC, Moreira J, Trasi S, Visintainer P, Cavaliere R. M. Grundman $O$ anel aberto: um novo sinal de imagem em doença desmielinizante. J Neuroimagem 1996;6:104-107

24 Heyman D, Delhaye M, Fournier D, Mercier P, Rousselet MC, Menei P. Pseudotumoral demyelination: a diagnosis pitfall (report of three cases). J Neurooncol 2001;54:71-76

25 Pakos EE, Tsekeris PG, Chatzidimou K, et al. Astrocytoma-like multiple sclerosis. Clin Neurol Neurosurg 2005;107(2):152-157

26 Lie JT. Primary (granulomatous) angiitis of the central nervous system: a clinicopathologic analysis of 15 new cases and a review of the literature. Hum Pathol 1992;23:164-171

27 Alrawi A, Trobe JD, Blaivas M, Musch DC. Biópsia do cérebro com vasculite primária do sistema nervoso central. Neurocirurgia 1999;53:858-860

28 Bennett DL, McCabe DJ, Stevens JM, Mifsud V, Cozinha ND, Giovannoni G. Tumefactive neuro-Behcet disease. Neurology 2004;63:709

29 Bornemann A, Bohl J, Hey O, et al. Amyloidoma of the gasserian ganglion as a cause of symptomatic neuralgia of the trigeminal nerve: report of three cases. J Neurol 1993;241:10-14

30 Matsumoto T, Tani E, Fukami M, Kaba K, Yokota M, Hoshii Y. Amyloidoma in the gasserian ganglion: case report. Surg Neurol 1999;52:600-603

31 Vorster SJ, Lee JH, Ruggieri P. Amyloidoma of the gasserian ganglion. AJNR Am J Neuroradiol 1998;19(10):1853-1855

32 Mullins ME, Barest GD, Schaefer PW, Hochberg FH, Gonzalez RG, Lev $\mathrm{MH}$. Radiation necrosis versus glioma recurrence: conventional MR imaging clues to diagnosis. AJNR Am J Neuroradiol 2005;26:1967-1972

33 Sugahara T, Koorogui Y, Tomiguchi S, et al. Posttherapeutic intraaxial brain tumor: the value of perfusion-sensitive contrastenhanced MR imaging for differentiating tumor recurrence from nonneoplastic contrast-enhancing tissue. AJNR Am J Neuroradiol 2000;21:901-909

34 Hausler M, Schaade L, Ramaekers VT, Doenges M, Heimann G, Sellhaus B. Inflammatory pseudotumors of the central nervous system: report of 3 cases and a literature review. Hum Pathol 2003;34:253-262

35 Shah MD, McClain KL. Intracranial plasma cell granuloma: case report and treatment of recurrence with methotrexate and 6mercaptopurine. J Pediatr Hematol Oncol 2005;27:599-603

36 Matsumura K, Nakasu S, Tanaka T, Nioka H, Matsuda M. Intracranial localized Castleman's disease: case report. Neurol Med Chir (Tokyo) 2005;45:59-65

37 Hashimoto H, lida J, Hironaka Y, Sakaki T. Intracranial Castleman's disease of solitary form: case report. J Neurosurg 1999;90:563-566

38 Sotrel A, Castellano-Sanchez AA, Prusmack C, Birchansky S, Brathwaite C, Ragheb J. Castleman's disease in a child presenting with a partly mineralized solitary meningeal mass. Pediatr Neurosurg 2003;38:232-237

39 Kattner KA, Stroink AR, Roth TC, Lee JM. Rosai-Dorfman disease mimicking parasagittal meningioma: case presentation and review of literature. Surg Neurol 2000;53:452-457; discussion 457

40 McClain KL, Natkunam Y, Swerdlow SH. Atypical cellular disorders. Hematology Am Soc Hematol Educ Program 2004:283-296

41 Gies U, Gruia D, Lassmann H, Bergmann M. A case of rapidly progressive Rosai-Dorfman disease restricted to the central nervous system. Zentralbl Neurochir 2005;66:142-146

42 Wu M, Anderson AE, Kahn LB. A report of intracranial Rosai-Dorfman disease with literature review. Ann Diagn Pathol 2001;5:96-102 